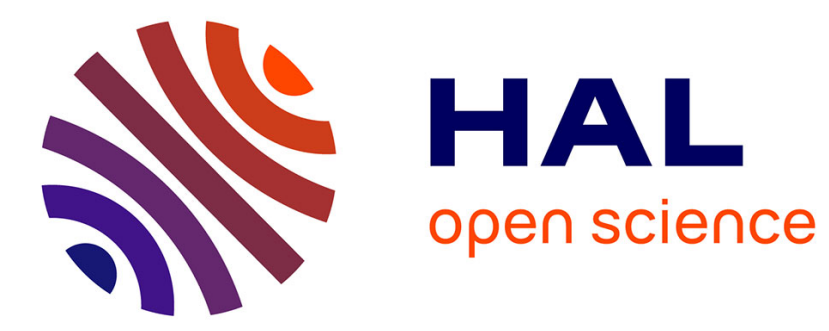

\title{
New insight on early oxidation stages of austenitic stainless steel from in situ XPS analysis on single-crystalline $\mathbf{F e}-\mathbf{1 8 C r}-13 \mathrm{Ni}$
}

Li Ma, Frédéric Wiame, Vincent Maurice, Philippe Marcus

\section{To cite this version:}

Li Ma, Frédéric Wiame, Vincent Maurice, Philippe Marcus. New insight on early oxidation stages of austenitic stainless steel from in situ XPS analysis on single-crystalline $\mathrm{Fe}-18 \mathrm{Cr}-13 \mathrm{Ni}$. Corrosion Science, 2018, 140, pp.205-216. 10.1016/j.corsci.2018.06.001 . hal-02349690

\section{HAL Id: hal-02349690 \\ https://hal.science/hal-02349690}

Submitted on 7 Nov 2019

HAL is a multi-disciplinary open access archive for the deposit and dissemination of scientific research documents, whether they are published or not. The documents may come from teaching and research institutions in France or abroad, or from public or private research centers.
L'archive ouverte pluridisciplinaire HAL, est destinée au dépôt et à la diffusion de documents scientifiques de niveau recherche, publiés ou non, émanant des établissements d'enseignement et de recherche français ou étrangers, des laboratoires publics ou privés. 


\title{
New insight on early oxidation stages of austenitic stainless steel from in situ XPS analysis on single-crystalline Fe-18Cr-13Ni
}

\author{
Li Ma, Frédéric Wiame, Vincent Maurice*, Philippe Marcus \\ PSL Research University, CNRS-Chimie ParisTech, Institut de Recherche de Chimie Paris (IRCP), \\ Research Group of Physical Chemistry of Surfaces, 75005 Paris, France
}

\begin{abstract}
In situ X-ray photoelectron spectroscopy real-time measurements and angular-dependent high resolution core level analysis were used for the first time to investigate the Cr enrichment and oxide growth mechanisms on a model 304 austenitic stainless steel surface in the very initial stages of oxidation leading to pre-passivation. The oxidation kinetics was followed for increasing oxygen exposure and temperature, revealing an early nucleation regime (for exposure $<10 \mathrm{~L}$ ) leading to the formation of a strongly $\mathrm{Cr}$-enriched $\mathrm{Cr}^{3+} / \mathrm{Fe}^{3+}$ mixed layer followed by an oxide growth regime where preferential iron oxidation takes over and mitigate the initial chromium enrichment.

Keywords: In situ X-ray photoelectron spectroscopy (XPS); stainless steel; single crystal surface; oxidation kinetics; Cr enrichment; growth mechanism
\end{abstract}

\section{Introduction}

Stainless steels (FeCr-based alloys) are widely used because of their high corrosion resistance resulting from the formation of a continuous and protective surface oxide layer, the passive film. Numerous surface analytical studies have shown that the passive film is only a few nanometers thick and markedly enriched in Cr(III) oxide/hydroxide species [1-13]. Recently, it has been suggested from nanometer scale studies on austenitic stainless steels that

\footnotetext{
${ }^{*}$ Corresponding author

Email addresses: li.ma@chimieparistech.psl.eu (Li Ma), frederic.wiame@chimieparistech.psl.eu (Frédéric Wiame), vincent.maurice@chimieparistech.psl.eu (Vincent Maurice), philippe.marcus@chimieparistech.psl.eu (Philippe Marcus)

Paper accepted to Corrosion Science
} 
the $\mathrm{Cr}$ enrichment, which is the key factor for the corrosion resistance, may not be homogeneous in the oxide film $[14,15]$. The pre-passivation mechanism by which the native oxide is initially formed most often in air may produce enrichment heterogeneities at the origin of the failure of the corrosion resistance by initiation of localized corrosion. Thus it appears essential to thoroughly investigate the initial stages of oxidation (i.e. pre-passivation) of the alloy surface under well-controlled temperature and exposure conditions, as well as the mechanisms governing the Cr enrichment.

Most studies [16-22] on the initial oxidation of pure iron and Fe-based alloys (mostly FeCr alloys) have been carried out with a surface science approach in ultra-high vacuum (UHV) conditions, because it provides a maximal control of surface state and oxidation conditions which are key factors to surface reactivity and growth mechanism studies of ultra-thin oxide films. Polycrystalline alloys for practical applications were investigated despite the fact that single crystal surfaces enable a deeper insight to the surface composition and to the oxide formation process since limiting the complexity brought by dissimilar crystallographic orientations, grain boundaries, second phase particles and impurities. Only very few studies have been conducted on stainless steel single crystals $[4,15,20,23,24]$.

X-ray Photoelectron Spectroscopy (XPS) is commonly applied to analyze surface chemical states and composition. Numerous XPS analyses provided chemical states references on $\mathrm{Cr}, \mathrm{Fe}$ and Ni metals, as well as their various oxides [4, 5, 15, 23, 25-33]. For the alloy surface composition, it was concluded from previous works focused on the proportion of formed $\mathrm{Cr}$ oxides and $\mathrm{Fe}$ oxides that the formation of $\mathrm{Cr}$ oxides is thermodynamically favored while that of Fe oxides is kinetically controlled $[34,35]$. The stratification of oxide films can be analyzed by angle-resolved XPS (ARXPS). For example, Castle et al. [31] have determined the in-depth distribution of oxides species according to a surface model determined from ARXPS measurements. However, there is almost no stratification analysis of surface region during the very first stages of oxidation.

Previous studies have also shown that oxidation temperature and oxygen exposure are two key factors for the oxidation rate, surface composition and oxides structure $[16,19,20$, $22,36]$. Most previous works were carried out at room temperature (RT) $[16,17,24,37]$ 
and around $300^{\circ} \mathrm{C}[20,22,37]$, the latter because of its industrial relevance. However, no oxidation study of Fe-Cr-Ni alloys was conducted systematically at different temperatures.

Regarding oxygen exposure, experiments were carried out at values larger than $1000 \mathrm{~L}$ ( $\left.1 \mathrm{~L}=1.33 \times 10^{-6} \mathrm{mbar} \cdot \mathrm{s}\right)$, under oxygen pressure usually higher than $10^{-6} \mathrm{mbar}$. According to our kinetics data presented hereafter, this is far beyond the initial stages of oxidation, defined as the range of exposure for which the surface varies the most. The understanding of the mechanisms of oxide growth and $\mathrm{Cr}$ enrichment in the initial stages of oxidation is essential to understand the structure and properties of ultra-thin oxide films. However, to the best of our knowledge, there was no investigation of Fe-Cr-Ni alloy surfaces during and/or after very low oxygen exposure $(<100 \mathrm{~L})$, neither of the mechanism of ultra-thin oxide film formation.

Nitrogen segregation has been observed in some studies performed on N-containing stainless steel $[22,38-40]$ and resulted in the formation of surface chromium nitride compounds. It was deduced by some authors that the co-segregation of chromium with nitrogen could increase the proportion of surface chromium oxides [41].

Here, we bring new insight on the oxidation kinetics and evolution of the surface composition and stratification during the initial oxidation of austenitic stainless steel. Nitrogen segregation is also discussed. The study was performed by in situ XPS on a (100)-oriented Fe-18Cr-13Ni single crystal (a model of the most common 304 grade of austenitic stainless steel) during the initial stages of oxygen exposure $(<100 \mathrm{~L})$ at $\mathrm{RT}, 150^{\circ} \mathrm{C}$ and $250^{\circ} \mathrm{C}$. The work is aimed at providing new comprehensive knowledge for the surface treatments of Fe-Cr-Ni alloys for improved resistance to initiation of localized corrosion of stainless steel.

\section{Experimental}

Firstly, the clean surface and nitrogen segregation were characterized. Then, the evolution of the oxygen uptake during oxygen exposure was monitored in situ to determine the oxidation kinetics. For that purpose, a novel specific XPS acquisition mode was adopted to record the real-time evolution of the photoelectron spectra during oxidation. In this way, 
the continuity of signal variation was achieved which strengthened greatly the kinetics monitoring. Afterwards, oxidation was conducted at exposures selected according to the kinetics data. The high resolution spectra were decomposed in order to determine the chemical states and their proportions. Based on angle-resolved data, oxide models were proposed to discuss the surface composition and stratification, as well as the thickness and formation mechanism of the oxide films and their Cr enrichment. A complementary Scanning Tunneling Microscopy (STM) study of the local topographical and structural alterations of the surface brought by initial oxidation will be reported separately [42].

The experiments were performed in a multi-chamber UHV system including a preparation chamber and two analysis chambers (XPS chamber and STM chamber), maintaining a base pressure $<10^{-10}$ mbar. The preparation chamber is equipped with an $\mathrm{Ar}^{+}$cold cathode ion gun for sputtering and resistive heating filament for annealing. Samples are heated from back side and temperature is controlled through a thermocouple attached on the manipulator in contact with the sample.

A (100)-oriented Fe-18Cr-13Ni single crystal with $99.999 \%$ purity was used. The sample was mechanically and electrochemically polished before introduction in the UHV system (procedure described elsewhere [23]). After introduction, the sample surface was cleaned by cycles of $\mathrm{Ar}^{+}$ion sputtering $\left(1 \mathrm{kV}, 10 \mu \mathrm{A}, 10\right.$ minutes) and annealing $\left(700^{\circ} \mathrm{C}, 10\right.$ minutes) in the preparation chamber. Sputtering and annealing cycles were applied between each oxidation experiment. The chemical and structural quality of the surface were controlled by XPS and low energy electron diffraction (LEED), respectively.

Gaseous oxygen (99.999\% purity) was introduced via a leak valve directly connected to the preparation chamber or via an oxidation cell installed in the XPS analysis chamber. XPS analysis was conducted with the Argus spectrometer, using the monochromatic XM1000 Mkll Al K $\alpha$ X-ray source (1486.6 eV) both from Scienta Omicron. The Argus detector with 128 channels has a high spatial resolution and a high counting rate that allow to record electron spectra over short time period. The in situ XPS investigations were carried out using the Snapshot detection mode, recording a spectrum every 10 seconds in real-time monitoring during oxidation. Thousands of spectra were recorded to describe the variation 
of oxygen (or nitrogen) peak intensity during oxidation (or annealing). Most of oxidation treatments were carried out at RT, $150^{\circ} \mathrm{C}$ and $250^{\circ} \mathrm{C}$ with $\mathrm{O}_{2}$ pressure $\leq 10^{-8}$ mbar. Such low oxygen pressure was kept in order to monitor the 0-100 L exposure range with good precision. The pressure in the chamber was continuously recorded and the exposure to $\mathrm{O}_{2}$ was calculated from the integration of oxygen pressure as a function of oxidation time.

According to the in situ kinetics data, series of oxidations under very low oxygen exposures were carried out for detailed chemical analysis of the surface evolution. Survey and high resolution spectra of Fe 2p, Cr 2p, Ni 2p, O 1s, N 1s and C 1s core levels were recorded after each oxidation treatment, with constant pass energy of $50 \mathrm{eV}$ and $20 \mathrm{eV}$, respectively. Both take-off angles of $45^{\circ}$ and $90^{\circ}$ were studied in order to determine the distribution of species along the direction normal to the surface. All obtained XPS spectra were referenced to the Fermi edge. Three exposures less than $10 \mathrm{~L}$ and nine exposures above were chosen for decomposition analyses. More than 400 high-resolution spectra were recorded and analyzed in this work. After exposure to about $300 \mathrm{~L}$ at $250^{\circ} \mathrm{C}$, no more significant change in the substrate signal was observed.

Data analyses were performed using the CasaXPS software (Version 2.3.17) [43]. For reconstruction of the high resolution spectra, several constraints were considered to achieve accuracy and consistency.

The width of analyzed regions was carefully adjusted to ensure a suitable background contribution. For $\mathrm{Fe}$ and $\mathrm{Cr}$, the $2 \mathrm{p}$ core levels were fitted by adjusting the intensity ratio between $2 \mathrm{p}_{3 / 2}$ and $2 \mathrm{p}_{1 / 2}$ components to values matching the theoretical ratio. For nickel, as there was no overlapping between the $2 \mathrm{p}_{3 / 2}(852.8 \mathrm{eV})$ and $2 \mathrm{p}_{1 / 2}(869.6 \mathrm{eV})$ peaks, only $\mathrm{Ni}$ $2 \mathrm{p}_{3 / 2}$ was considered. In order to improve the accuracy of the quantitative determination, only the $2 \mathrm{p}_{3 / 2}$ data were used to calculate the concentration and to establish the oxide model as $2 \mathrm{p}_{1 / 2}$ components have larger uncertainties.

Background subtraction methods can influence the quantitative values of $\mathrm{Fe}$ and $\mathrm{Cr}$ chemical states concentrations $[25,31,44,45]$. It was found that the chemical states proportions extracted by using different background subtraction can vary by $\pm 5 \%$ for iron oxide and $\pm 3 \%$ for chromium oxide [25]. To minimize the effect of background subtraction on 
components concentration, an adjustable Shirley background [46] was adopted for our peak fitting.

A Lorentzian asymmetric line shape, with the same asymptotic behavior as DoniachŠnjić component [47], convoluted by a Gaussian shape was used for fitting the metallic component peaks. The indexes of asymmetry follow the order: metal $>$ oxide $>$ satellite $\approx$ 0. A simple product of Gaussian and Lorentzian line shapes was used for the non-metallic components.

Binding energy (BE) and full width at half maximum (FWHM) are two important parameters affecting the reconstruction of the synthetic curve shape. Although metal compounds states have been largely studied by XPS [25-31, 35], BE and FWHM can be different according to the used sample and spectrometer. There are few data in the literature about the BE position of $2 \mathrm{p}_{1 / 2}$ core level peaks and shake-up satellite peaks. As for FWHM, it depends on the chemical environment. Normally, the FWHM values of the different peaks follow the order: satellite $>$ oxide(nitride) $>$ metal and $2 \mathrm{p}_{1 / 2}>2 \mathrm{p}_{3 / 2}$.

Once the fitting parameters were determined, they were fixed for all the high-resolution spectra recorded at take-off angles of $45^{\circ}$ and $90^{\circ}$. Only the relative peak intensities were treated as the variable for peak fitting.

\section{Results and discussion}

\subsection{XPS fitting parameters}

Table 1 compiles the fitting parameters determined from the XPS spectra reconstruction. They are consistent with typical values found in other works $[25,28,29]$. The chemical shifts of the different $\mathrm{Fe}$ oxides with respect to $\mathrm{Fe}^{0}$ metal are $1.7 \mathrm{eV}, 2.6 \mathrm{eV}$ and $3.5 \mathrm{eV}$ for the components assigned to $\mathrm{Fe}^{2+}$ (in $\mathrm{Fe}_{3} \mathrm{O}_{4}$ matrix), $\mathrm{Fe}^{2+}$ (in FeO-like matrix) and $\mathrm{Fe}^{3+}\left(\right.$ in $\mathrm{Fe}_{2} \mathrm{O}_{3}$ matrix), respectively. Spin orbit splitting is $13.1 \mathrm{eV}$ between the Fe $2 \mathrm{p}_{3 / 2}$ and Fe $2 \mathrm{p}_{1 / 2}$ main peaks and $13.5 \mathrm{eV}$ between the $\mathrm{Fe} 2 \mathrm{p}_{3 / 2}$ and $\mathrm{Fe} 2 \mathrm{p}_{1 / 2}$ shake-up satellite peaks, which is close to the values from recent studies $[25,26,28,31,35]$. BE separations between the Fe $2 \mathrm{p}_{3 / 2}$ main peaks and $\mathrm{Fe} 2 \mathrm{p}_{3 / 2}$ satellite peaks are $4.5 \mathrm{eV}$ and $5.9 \mathrm{eV}$ for $\mathrm{Fe}^{2+}$ and $\mathrm{Fe}^{3+}$, respectively. 
Table 1 Fitting parameters obtained by reconstruction of the XPS core level spectra

\begin{tabular}{|c|c|c|c|c|}
\hline Core level & State & $\mathrm{BE}( \pm 0.1 \mathrm{eV})$ & FWHM $( \pm 0.1 \mathrm{eV})$ & Asymmetry index \\
\hline \multirow{6}{*}{ Fe $2 p_{3 / 2}$} & $\mathrm{Fe}^{0}$ & 706.8 & 0.8 & 0.59 \\
\hline & $\mathrm{Fe}^{2+}\left(\mathrm{Fe}_{3} \mathrm{O}_{4}\right)$ & 708.5 & 1.5 & 0.31 \\
\hline & $\mathrm{Fe}^{2+}(\mathrm{FeO}-$ like $)$ & 709.4 & 2.1 & 0.31 \\
\hline & $\mathrm{Fe}^{3+}\left(\mathrm{Fe}_{2} \mathrm{O}_{3}\right)$ & 710.3 & 3.1 & 0.42 \\
\hline & $\mathrm{Fe}^{2+}$ satellite & 713.0 & 4.0 & 0.13 \\
\hline & $\mathrm{Fe}^{3+}$ satellite & 716.2 & 4.3 & 0.21 \\
\hline \multirow{4}{*}{ Cr $2 \mathrm{p}_{3 / 2}$} & $\mathrm{Cr}^{0}$ & 573.8 & 1.1 & 0.61 \\
\hline & $\mathrm{Cr}^{3+}(\mathrm{CrN})$ & 575.6 & 2.0 & 0.19 \\
\hline & $\mathrm{Cr}^{3+}\left(\mathrm{Cr}_{2} \mathrm{O}_{3}\right)$ & 576.5 & 2.0 & 0.46 \\
\hline & $\mathrm{Cr}^{3+}$ satellite & 588.3 & 3.5 & 0.00 \\
\hline Ni $2 p_{3 / 2}$ & $\mathrm{Ni}^{0}$ & 852.8 & 0.9 & 0.31 \\
\hline \multirow{4}{*}{$\mathrm{N}$ 1s } & $\mathrm{CrN}_{\text {surface }}$ & 396.6 & 1.1 & \multirow{4}{*}{0.00} \\
\hline & $\mathrm{CrN}_{b u l k}$ & 397.2 & 0.7 & \\
\hline & $\mathrm{N}_{\text {bulk }}$ & 397.8 & 0.7 & \\
\hline & $\mathrm{N}_{\text {minority }}$ & $398.5-400.5$ & $1.8-2.6$ & \\
\hline
\end{tabular}

This is $1-2 \mathrm{eV}$ smaller than for pure $\mathrm{Fe}_{3} \mathrm{O}_{4}$ and $\mathrm{Fe}_{2} \mathrm{O}_{3}$ oxide samples like pointed out by Aronniemi et al. [25].

For chromium, the chemical shift is $1.8 \mathrm{eV}$ for $\mathrm{Cr}^{3+}(\mathrm{CrN})$ and $2.7 \mathrm{eV}$ for $\mathrm{Cr}^{3+}$ oxide $\left(\mathrm{Cr}_{2} \mathrm{O}_{3}\right)$. These values are of the order reported in the literature [5, 25, 27, 28, 30]. Spinorbit splitting between the $\operatorname{Cr} 2 \mathrm{p}_{3 / 2}$ and $\mathrm{Cr} 2 \mathrm{p}_{1 / 2}$ peaks are $9.4 \mathrm{eV}, 9.5 \mathrm{eV}, 9.6 \mathrm{eV}$ and $9.0 \mathrm{eV}$ for $\mathrm{Cr}^{0}, \mathrm{Cr}^{3+}(\mathrm{CrN}), \mathrm{Cr}^{3+}\left(\mathrm{Cr}_{2} \mathrm{O}_{3}\right)$ and $\mathrm{Cr}$ shake-up satellite peaks, respectively. BE separation for $\mathrm{Cr}$ satellite peak is $14.5 \mathrm{eV}$ which is $2-3 \mathrm{eV}$ smaller than reported from a $\mathrm{Cr}$ $2 \mathrm{p}$ curve fitting study of a pure $\mathrm{Cr}_{2} \mathrm{O}_{3}$ powder sample [25].

The $2 \mathrm{p}_{3 / 2}$ and $2 \mathrm{p}_{1 / 2}$ doublet intensity ratios for $\mathrm{Fe}$ and $\mathrm{Cr}$ vary from 0.49 to 0.52 , which is close to the theoretical value of 0.5 .

As for the FWHM, compared to the metallic peaks, it is confirmed that the oxide peaks are wider. Satellite peaks have larger FWHM values in the range about $3.5-4.3 \mathrm{eV}$ due to the strong overlap with the main peaks and the background. The metallic peaks contribute 
a lot to the asymmetry of the spectra.

\subsection{Clean surface characterization and nitrogen segregation}

After $\mathrm{Ar}^{+}$sputtering the alloy surface, only the $\mathrm{Fe} 2 \mathrm{p}, \mathrm{Cr} 2 \mathrm{p}$ and $\mathrm{Ni} 2 \mathrm{p}$ core levels were identified indicating the absence of contaminants. No carbon or nitrogen were detected. It proves that the nominal amounts of these elements are below the detection limit of the XPS $(<0.5$ at $\%)$. The surface composition (at\%) was determined as $75 \mathrm{Fe}-15 \mathrm{Cr}-10 \mathrm{Ni}$, depleted in $\mathrm{Cr}$ at the surface compared to the nominal bulk value $(69 \mathrm{Fe}-18 \mathrm{Cr}-13 \mathrm{Ni})$. However, after annealing at $700^{\circ} \mathrm{C}$ for 10 minutes, a $\mathrm{N}$ 1s feature appeared at around $397.2 \mathrm{eV}$, indicating that nitrogen, below the detection limit after sputtering, segregated on the surface upon thermal treatment. The details of the Fe 2p, Cr 2p, Ni $2 p$ and $\mathrm{N} 1$ s spectra are discussed in Section 3.4. The composition of the surface obtained after annealing was (at\%) $54 \mathrm{Fe}-$ 29Cr-9Ni with 8 at\% N. It should be noted that these composition values were deduced from quantitative analysis of the XPS spectra assuming an identical surface distribution for all elements. Their relative changes evidence that $\mathrm{Cr}$ and $\mathrm{N}$ segregate at the surface upon annealing. The form under which these elements segregate will be discussed in section 3.4.

Fig. 1 depicts the real-time segregation of nitrogen at the surface as illustrated by the plot of the normalized area of N 1s peak versus annealing time (Fig. 1 (a)) and the variation of the segregation rate as a function of annealing temperature (Fig. 1 (b)). The data were acquired in three successive experiments (as seen from the two discontinuities in the plots) using the XPS Snapshot mode.

Fig. 1 (a) shows that the nitrogen intensity markedly increases from $400-500^{\circ} \mathrm{C}$ and reaches saturation at about $680^{\circ} \mathrm{C}$, which is in agreement with surface segregation of nitrogen reported after annealing a Fe-Cr alloy at $527^{\circ} \mathrm{C}[22]$. When the temperature exceeds about $680^{\circ} \mathrm{C}$, the $\mathrm{N}$ surface concentration remains unchanged. Compared to the surface annealed at $700^{\circ} \mathrm{C}$ during $10 \mathrm{~min}$, the surface saturated at $680^{\circ} \mathrm{C}$ has the same amount of nitrogen.

Fig. 1 (b) provides more details on the variation of the nitrogen surface uptake. It shows that the segregation rate, as given by $\frac{\mathrm{dN}}{\mathrm{d} t}$, the derivative of the normalized area of the $\mathrm{N} 1 \mathrm{~s}$ peak with respect to time, begins to increase at about $400^{\circ} \mathrm{C}$ and reaches its maximum at 

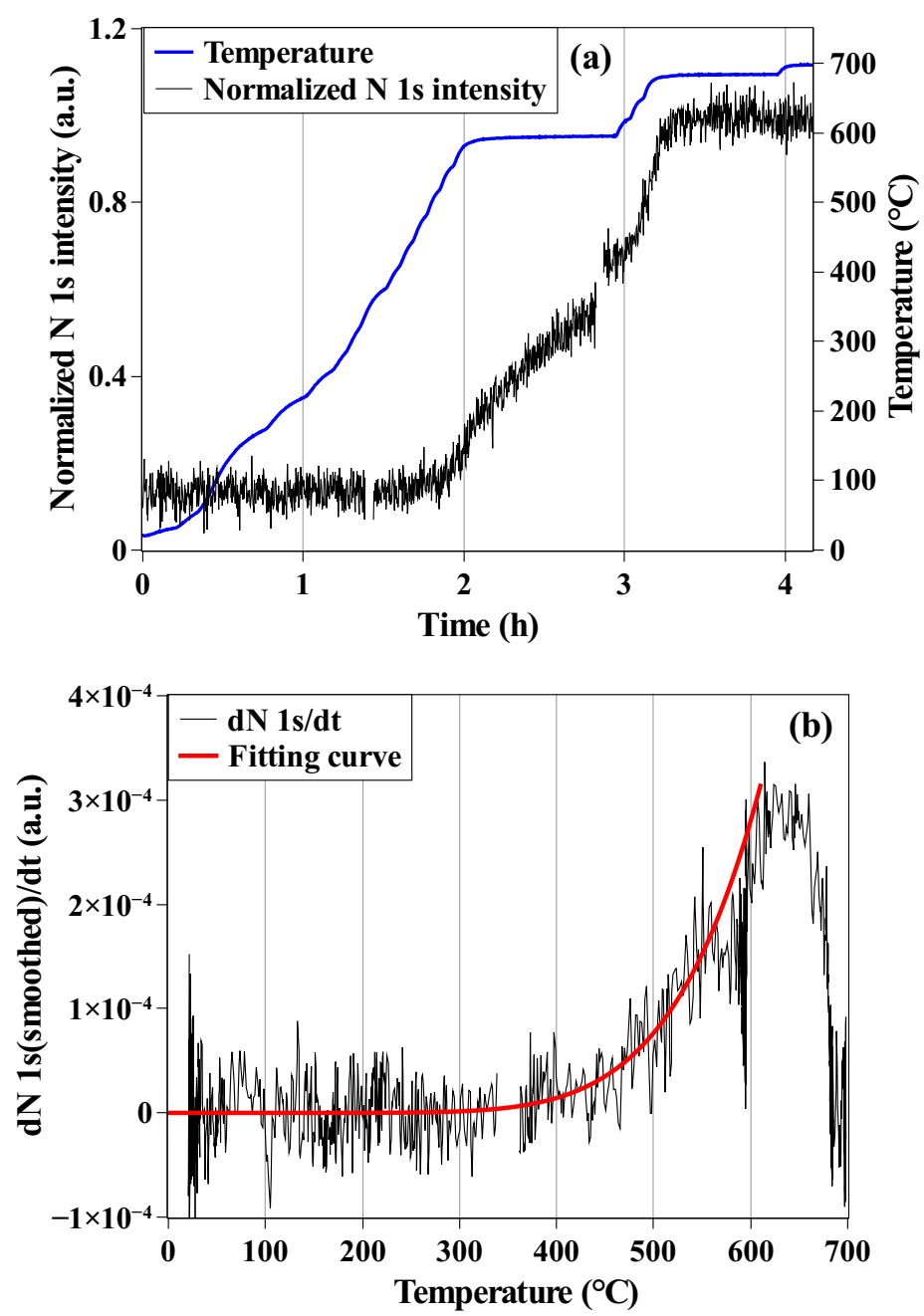

Fig. 1. Real-time nitrogen segregation on Fe-18Cr-13Ni(100) as measured by XPS in Snapshot mode upon annealing the sputter-cleaned surface: (a) variation of normalized N 1s intensity, (b) nitrogen segregation rate and fitting curve (see text for details). 
about $620^{\circ} \mathrm{C}$ before dropping quickly to zero after surface saturation at $680^{\circ} \mathrm{C}$, showing that nitrogen segregation depends effectively on temperature. Since nitrogen starts to segregate at $400^{\circ} \mathrm{C}$, it is nearly impossible to prepare an annealed and well-structured metallic surface that is nitrogen-free. As shown in Fig. 1 (b), the nitrogen segregation kinetics plot can be fitted by the following equation:

$$
\frac{\mathrm{dN}}{\mathrm{d} t}=A \exp \frac{-E}{k T}
$$

where $k$ is the Boltzmann constant and $E$ the activation energy for $\mathrm{N}$ segregation. The fitted value of $E$ is $72 \pm 5 \mathrm{~kJ} / \mathrm{mol}$. This is less than the value found for $\mathrm{N}$ segregation in a ferritic Fe-Mo alloy [48]. The N saturation of the oxide-free surface would therefore be easier to achieve in our case of an austenitic alloy.

Previous studies have discussed the influence of nitrogen on oxidation and wet corrosion of stainless steel $[5,22,38,40,41]$. It was reported that $\mathrm{Cr}$ and $\mathrm{N}$ co-segregate at the surface, as confirmed in the present work, which may promote the selective oxidation of metallic $\mathrm{Cr}$ enriched at the co-segregated surface. $\mathrm{Cr}$ and $\mathrm{N}$ co-segregate in the form of chromium nitride compounds [22, 40, 41], which is discussed in the following.

\subsection{Surface oxidation kinetics}

In order to determine the influence of oxygen pressure and temperature during the initial oxidation of the $\mathrm{Fe}-18 \mathrm{Cr}-13 \mathrm{Ni}(100)$ surface, oxidation runs were performed at $\mathrm{RT}, 150^{\circ} \mathrm{C}$ and $250^{\circ} \mathrm{C}$ at different oxygen pressures on the sample surface pre-annealed at $700^{\circ} \mathrm{C}$. Fig. 2 presents the evolution of the normalized $\mathrm{O}$ 1s peak area at these three temperatures as a function of $\mathrm{O}_{2}$ exposure $(100 \mathrm{~L})$ as measured in real-time by in situ XPS. Fig. 2 (b) enlarges the region of the first $25 \mathrm{~L}$ of exposure. This is the first observation of oxidation kinetics at the very early stage. In previous studies, oxidation experiments of iron or stainless steel were carried out at $\mathrm{P}_{\mathrm{O}_{2}}>10^{-6}$ mbar $[20,21,24,39,49]$. At these pressures, the detailed information on oxide film growth in the very first stages is lost. This is why our study was limited to $10^{-8}$ mbar for low exposures $(<100 \mathrm{~L})$ and did not exceed $10^{-6}$ mbar for larger ones, as shown by the insets in Fig. 2 (a). Since there was no evidence of discontinuity in 

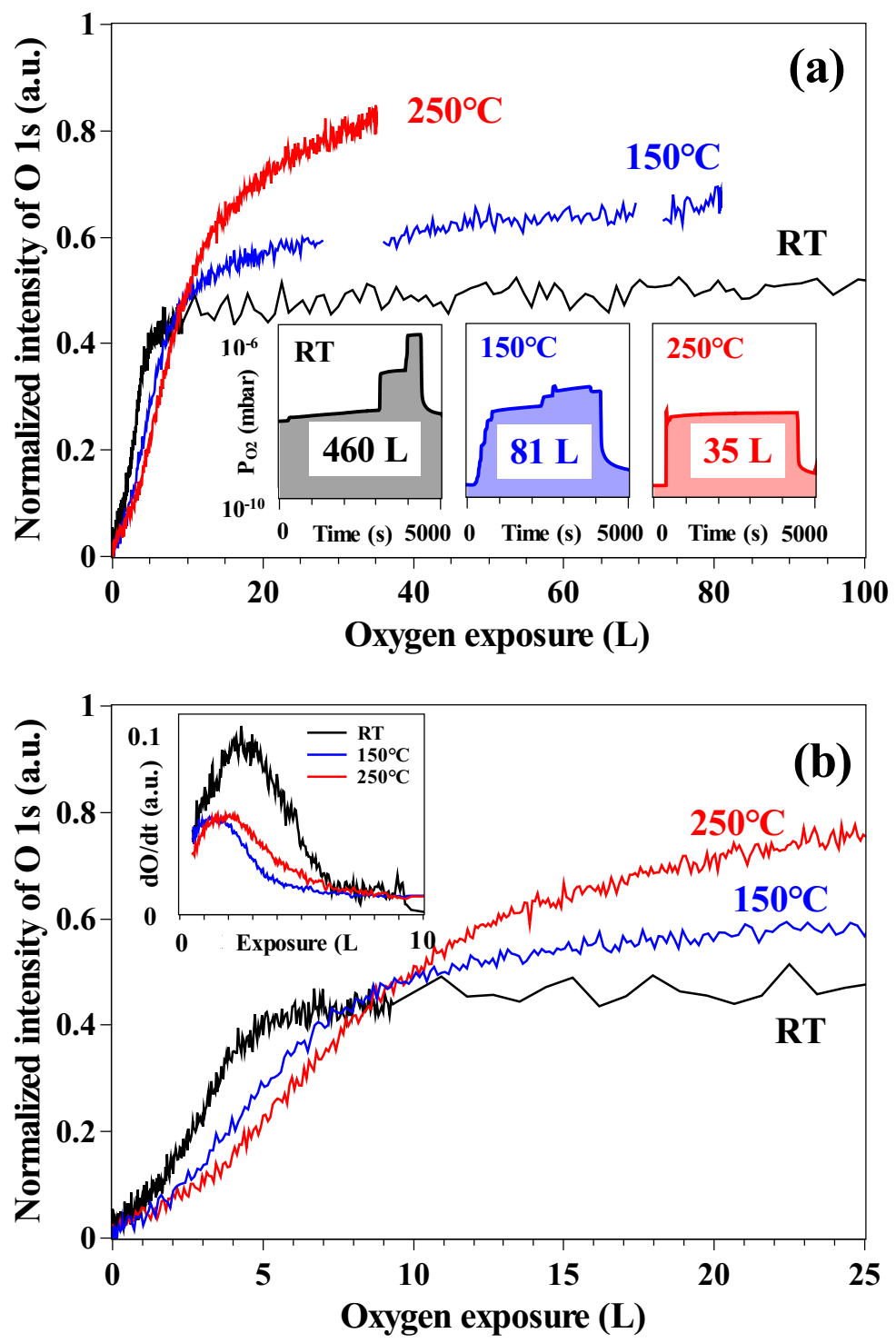

Fig. 2. Real-time oxygen uptake on Fe-18Cr-13Ni(100) as measured by XPS in Snapshot mode during oxidation: (a) normalized intensity of $\mathrm{O} 1 \mathrm{~s}$ as a function of $\mathrm{O}_{2}$ exposure in the 0-100 L range, (b) enlarged 0-25 L range. The time variation of the oxygen pressure is inserted in (a). The variation of oxidation rate with exposure is inserted in (b). 
the kinetic curves recorded at $\mathrm{RT}$ and $150^{\circ} \mathrm{C}$, the change of oxygen pressure is concluded to have no apparent influence on the oxidation kinetics in the conditions tested.

At a fixed temperature, the $\mathrm{O}$ 1s intensity first increases rapidly before slowing down and leveling. At RT, the oxygen uptake reaches saturation when oxygen exposure exceeds $10 \mathrm{~L}$ (Fig. 2 (b)). At $150^{\circ} \mathrm{C}$ or $250^{\circ} \mathrm{C}$, the oxygen uptake is reduced after exposure to $20 \mathrm{~L}$ (Fig. 2 (a)), but no oxidation saturation is observed upon oxygen exposure up to $81 \mathrm{~L}$ and to $35 \mathrm{~L}$, respectively. The inset in Fig. 2 (b) presents the oxygen uptake rate $\left(\frac{\mathrm{dO}}{\mathrm{d} t}\right)$ recorded in situ in the $0-10 \mathrm{~L}$ exposure range at the three temperatures. It shows that the oxidation rate reaches a maximum at 2-3 L exposure and then decreases to stabilize to around zero at $10 \mathrm{~L}$ at RT. At $150^{\circ} \mathrm{C}$ and $250^{\circ} \mathrm{C}$, a slow oxidation rate is still observed after $10 \mathrm{~L}$ exposure.

As evidenced in Fig. 2 (b), as the temperature increases, the initial oxygen uptake is reduced. This is consistent with the decrease of the physical adsorption time (Arrhenius law) with, as a consequence, the decrease of the reaction rate at very low exposure $(<10$ L). At RT, a component was detected at $531.4 \mathrm{eV} \mathrm{BE}$ in the $\mathrm{O}$ 1s region, close to the value attributed to adsorbed molecular oxygen [50]. This component, distinct from the oxide component peaks, was not observed in the spectra obtained at 150 and $250^{\circ} \mathrm{C}$ (Fig. $\mathrm{S} 1 \mathrm{in}$ supplementary data). This is consistent with the initial reduction of the sticking coefficient at these temperatures. In contrast, Fig. 2 (b) shows that for exposures larger than $10 \mathrm{~L}$, the oxygen uptake and its saturation level increase at higher temperature. This is consistent with higher temperature promoting atomic displacement at the surface and/or atomic transport between surface and sub-surface of the sample, thus resulting in the formation of more surface oxide by oxide growth.

Studies reported in the literature were carried out at $10^{-6}$ mbar or higher pressure for exposures larger than $1000 \mathrm{~L}[20,21,24]$, overlooking the initial stages of oxidation. Oxidation saturation was also observed by XPS on Fe(111) as recently reported by Davies et al. [21]. It was found that surface oxygen saturates after an oxygen exposure of about 100 $\mathrm{L}$ at $280 \mathrm{~K}$ (under $\mathrm{P}_{\mathrm{O}_{2}} \approx 10^{-6}$ mbar), whereas about $10 \mathrm{~L}$ are required to reach saturation on our alloy surface at RT. On Fe(111), the rate of oxygen uptake was almost the same at $280 \mathrm{~K}$ and $500 \mathrm{~K}$, but the oxygen coverage reached at $500 \mathrm{~K}$ is higher [21] in agreement with 
the increasing saturation level measured at $150^{\circ} \mathrm{C}$ and $250^{\circ} \mathrm{C}$ in the present work.

Thus, it is shown by in situ XPS analysis of the initial stages of the Fe- $18 \mathrm{Cr}-13 \mathrm{Ni}$ surface oxidation that there is no apparent effects of oxygen pressure on the oxidation kinetics in the tested pressure range $\left(<10^{-6} \mathrm{mbar}\right)$ and that the effects of temperature are different depending on oxygen exposure. The exposure of about $10 \mathrm{~L}$ can be estimated as the threshold below which the oxidation rate would be essentially limited by the sticking coefficient suggesting a nucleation phase reaching saturation at this exposure. Beyond 10 $\mathrm{L}$, atomic displacement and/or transport would become rate limiting suggesting that the oxidation process has entered the growth phase leading to the increase of the surface oxide formation with increasing temperature.

\subsection{Surface composition and oxidation mechanisms}

\subsubsection{Surface species and their evolution}

XPS high resolution core level analysis was performed at $45^{\circ}$ and $90^{\circ}$ take-off angles after cumulative exposure of the surface to oxygen in order to characterize the surface species and their evolution, as well as to quantify the surface composition. Based on the oxidation kinetics data presented above, the exposure series were of $0 \mathrm{~L}, 0.5 \mathrm{~L}, 3 \mathrm{~L}, 6 \mathrm{~L}, 9 \mathrm{~L}$ and 14 $\mathrm{L}$ at RT. At 150 and $250^{\circ} \mathrm{C}$, they were of $0 \mathrm{~L}, 3 \mathrm{~L}, 6 \mathrm{~L}, 9 \mathrm{~L}$ and $15 \mathrm{~L}$, complemented with series at 21 L, 35/37 L, 49/51 L, 76 L, 102/106 L, 221/224 L and 328/346 L. No carbon contamination was detected. The reconstruction of all Fe $2 \mathrm{p}, \mathrm{Cr} 2 \mathrm{p}$ and $\mathrm{N} 1$ s spectra (more than 300 spectra) was performed using the fitting parameters compiled in Table 1. Fig. 3 shows the reconstruction of Fe $2 \mathrm{p}, \mathrm{Cr} 2 \mathrm{p}$ and $\mathrm{N}$ 1s spectra measured at $45^{\circ}$ take-off angle after exposures of $0 \mathrm{~L}, 3 \mathrm{~L}, 6 \mathrm{~L}$ and $14 \mathrm{~L}$ at RT.

For the sake of clarity, the main peaks and satellites have been summed up for each oxidation state of $\mathrm{Fe}$ and $\mathrm{Cr}$. The $\mathrm{Fe}^{2+}$ and $\mathrm{Fe}^{3+}$ components were identified based on the spectra obtained at higher temperature where they are more prominent. Comparatively, the evolution of the Cr 2 p spectra was more marked at RT (as seen on Fig. 3), enabling the $\mathrm{Cr}^{3+}$ oxide and nitride components to be better identified.

The spectra presented in Fig. 3 show that the main cations in the surface oxide grown 

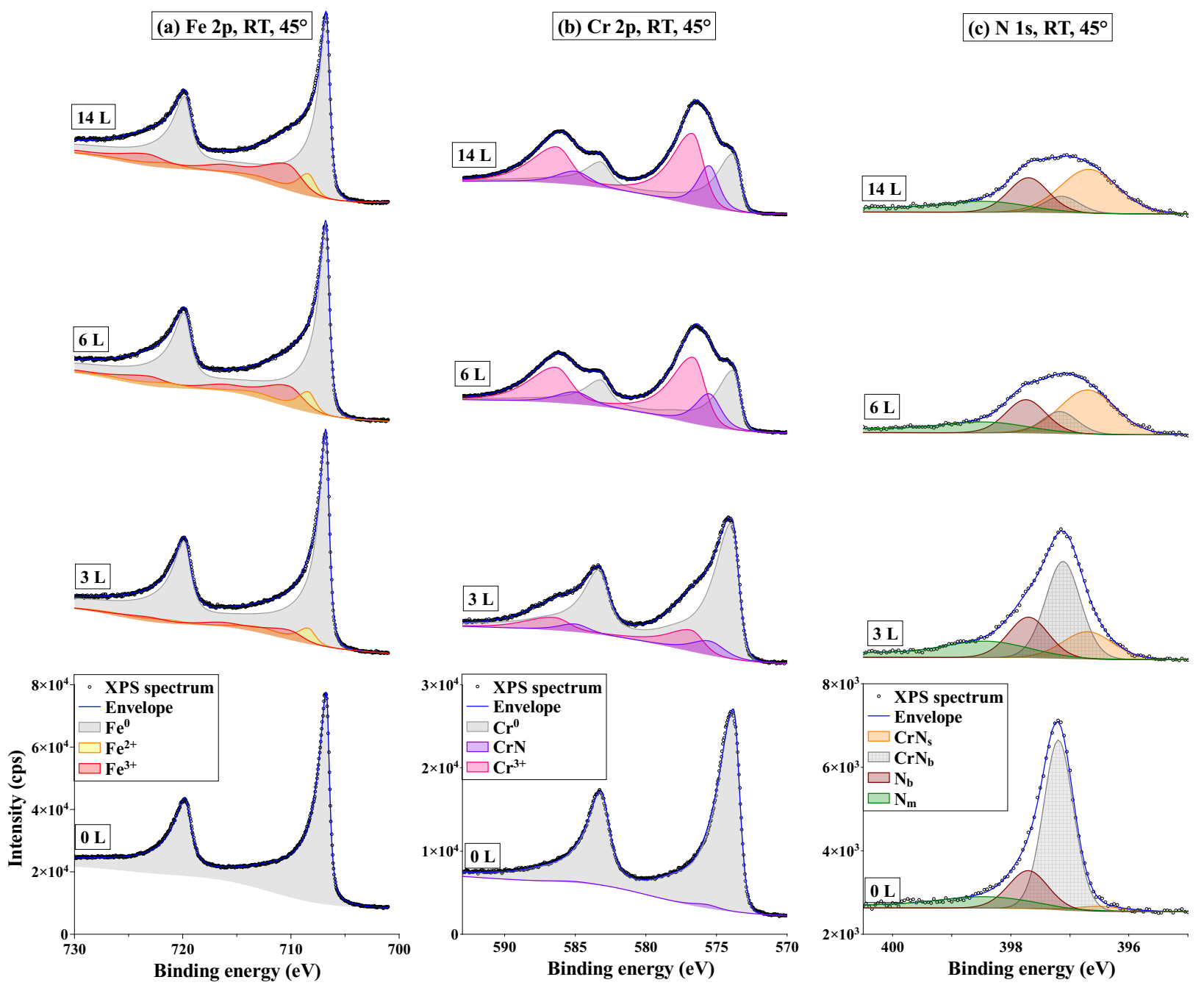

Fig. 3. Reconstruction of the XPS (a) Fe 2p, (b) Cr 2p, (c) N 1s core level regions for Fe-18Cr-13Ni(100) exposed to oxygen from 0 to $14 \mathrm{~L}$ at RT (take-off angle $45^{\circ}$ ). The $\mathrm{Fe}$ and $\mathrm{Cr}$ components are the sum of the main peaks and their satellites. Each component is represented by a colored and shaded area; the envelope indicates the sum of all component peaks; the dots represent the measured spectra. 
at $\mathrm{RT}$ are $\mathrm{Cr}^{3+}, \mathrm{Fe}^{2+}$ and $\mathrm{Fe}^{3+}$. No oxidized nickel $\left(\mathrm{Ni}^{2+}\right)$ was observed after oxidation since only a single metallic $\mathrm{Ni} 2 \mathrm{p}_{3 / 2}$ component was measured at $852.8 \mathrm{eV} \mathrm{BE}$ in agreement with previous studies $[20,23,24]$. Four nitrogen component peaks assigned to $\mathrm{CrN}_{b}, \mathrm{CrN}_{s}, \mathrm{~N}_{b}$ and $\mathrm{N}_{m}\left(\mathrm{CrN}_{\text {surface }}, \mathrm{CrN}_{\text {bulk }}, \mathrm{N}_{\text {bulk }}\right.$ and $\mathrm{N}_{\text {minority }}$ in Table 1) were also distinguished before and after oxygen exposure. For all core levels, there are no significant differences between the spectra at $6 \mathrm{~L}$ and $14 \mathrm{~L}$, indicating that the surface reaction reached saturation at $\mathrm{RT}$ in agreement with the in situ kinetics data presented in Fig. 2.

Even if one considers the uncertainty in the peak fitting, the spectra presented in Fig. 3 (a) yield a relative amount of $\mathrm{Fe}^{3+}$ and $\mathrm{Fe}^{2+}$ (e.g. $\mathrm{Fe}^{3+} / \mathrm{Fe}^{2+}$ intensity ratio of 1.4 at $3 \mathrm{~L}$ exposure) markedly below that (ratio of 2) corresponding to $\mathrm{Fe}_{3} \mathrm{O}_{4}$ which suggests the presence of non-stoichiometric mixed $\mathrm{Fe}^{2+}-\mathrm{Fe}^{3+}$ rather than $\mathrm{FeO}$ oxide nuclei prior to reaching saturation in agreement with the $709.4 \mathrm{eV} \mathrm{BE}$ value of $\mathrm{Fe}^{2+}$. As far as we know, the existence of $\mathrm{FeO}$ at the earlier stage of stainless steel oxidation is still under debate [1719, 36]. Several studies have demonstrated that the main surface compounds were $\mathrm{Fe}_{2} \mathrm{O}_{3}$ and $\mathrm{Fe}_{3} \mathrm{O}_{4}$ for iron oxidation under oxygen exposure larger than $10^{4} \mathrm{~L}$ [19]. On the contrary, the structure of $\mathrm{FeO}$ or FeO-like compounds were observed in studies [17, 18] addressing the conditions of $\mathrm{FeO}$ formation as compared to the phase diagram for the iron-oxygen system. Graat et al. [36] proposed the presence of FeO at RT for low oxygen exposure of $22 \mathrm{~L}$. Our finding of $\mathrm{Fe}^{2+}$ species is in agreement with this work [36] and that of Roosendaal et al. [18] but we also find $\mathrm{Fe}^{3+}$ species. Lin et al. [17] indicated that $\mathrm{FeO}_{x}$, the FeO-like oxide, was the nucleating oxide formed after low oxygen exposure $(10 \mathrm{~L}$ to $50 \mathrm{~L})$ at RT. The change of $x$ value implies that the oxygen-deficient $\mathrm{Fe}^{2+}-\mathrm{Fe}^{3+}$ mixed phases are first formed during the initial stages of oxidation and are transformed to $\mathrm{Fe}_{3} \mathrm{O}_{4}$ by further oxidation. We find that $\mathrm{Fe}^{2+}-\mathrm{Fe}^{3+}$ mixed oxide nuclei, possibly oxygen-deficient, are formed on the surface in the nucleation phase for oxygen exposures lower than $6 \mathrm{~L}$ for RT, 150 and $250^{\circ} \mathrm{C}$. At higher exposure, the $\mathrm{Fe}^{3+} / \mathrm{Fe}^{2+}$ intensity ratio is found consistent with the presence of $\mathrm{Fe}_{3} \mathrm{O}_{4}$ as well as the $\mathrm{BE}$ value of $\mathrm{Fe}^{2+}(709.4 \mathrm{eV})$. However, as discussed below, angle-resolved analysis points to a different in-depth repartition of the $\mathrm{Fe}^{3+}$ and $\mathrm{Fe}^{2+}$ species.

Fig. 3 (b) shows the development of $\mathrm{Cr}^{3+}$ oxide and nitride components during oxidation. 
$\mathrm{Cr}^{6+}$ species, expected at $579.3 \mathrm{eV} \mathrm{BE} \mathrm{[25],} \mathrm{were} \mathrm{not} \mathrm{found.} \mathrm{After} \mathrm{long} \mathrm{exposures} \mathrm{(>} 24$ 000 L), Fe-Cr mixed oxides were identified by Olefjord [51]. Lince et al. [16] have identified only one Fe 2 p peak varying at $709.5-710.8 \mathrm{eV}$ BE to determine the existence of $\mathrm{FeCr}_{2} \mathrm{O}_{4}$ or $\mathrm{Fe}_{1+x} \mathrm{Cr}_{2-x} \mathrm{O}_{4}$, for a Fe-16Cr(001) surface exposed to oxygen for more than $400 \mathrm{~L}$. Instead, two components at $709.4 \mathrm{eV}$ and $710.3 \mathrm{eV}$ were used for iron oxide peak reconstruction in our data. Thus the presence of $\mathrm{Fe}^{3+}$ and/or $\mathrm{Fe}^{2+}$ cations in the grown $\mathrm{Cr}^{3+}$ oxide matrix cannot be excluded. It is also observed in Fig. 3 that chromium oxidizes more rapidly than iron because of its higher oxide to metal intensity ratio when oxygen exposure is lower than $14 \mathrm{~L}$, i.e. in the nucleation phase. This is consistent with the results of Lince et al. [16].

Fig. 3 (c) presents the four identified nitrogen components: $\mathrm{CrN}_{b}, \mathrm{CrN}_{s}, \mathrm{~N}_{b}$ and $\mathrm{N}_{m}$. $\mathrm{CrN}_{b}$ is the main product of $\mathrm{Cr}-\mathrm{N}$ co-segregation at the surface. It is attributed to threedimensional clusters $[22,52,53]$ formed in the outer surface region including topmost and subsurface and hereafter referred to as bulk nitride. $\mathrm{CrN}_{s}$ corresponds to the two-dimensional CrN $[22,52,54]$ formed at the topmost surface and referred to as surface nitride. The peak at $397.8 \mathrm{eV} \mathrm{BE}$ is identified here as interstitial nitrogen $\mathrm{N}_{b}$ [22] rather than $\mathrm{Cr}_{2} \mathrm{~N}(397.6$ eV) $[5,22]$ due to the inconsistency of the $\mathrm{CrN}$ and $\mathrm{N}_{b}$ intensities. The broad component denoted $\mathrm{N}_{m}$ is identified in the decomposition of all spectra. Because of its broadness and low intensity, this component could originate from the sum of various minority contributions. At the very beginning of oxidation, mostly the $\mathrm{CrN}_{s}$ and barely the $\mathrm{N}_{b}$ components increase while the $\mathrm{CrN}_{b}$ component decreases markedly in intensity. As discussed above, nitrogen segregation saturation after annealing at $700^{\circ} \mathrm{C}$ of the sputtered surface causes the formation of a Cr-depleted region below the surface. This means that the increase of $\mathrm{CrN}_{s}$ and $\mathrm{N}_{b}$ components during oxidation is not the result of further nitrogen segregation from the bulk but the indication that the in-depth distribution of nitride has been modified by oxidation. The transformation from $\mathrm{CrN}_{b}$ to $\mathrm{CrN}_{s}$ and $\mathrm{N}_{b}$ is accelerated at $150^{\circ} \mathrm{C}$ and $250^{\circ} \mathrm{C}$. This variation of nitrogen species was also observed in previous studies of ferritic steel upon annealing [22] and assigned to the increasing instability of $\mathrm{CrN}_{b}$ with increasing annealing temperature. In summary, there is no nitrogen surface segregation during oxidation, rather the decomposition of $\mathrm{CrN}_{b}$ modifying the nitride in-depth distribution resulting from initial 
surface preparation.

Because of the complexity in oxide products, it was not attempted to distinguish the various $\mathrm{Cr}$ and $\mathrm{Fe}$ oxides according to the $\mathrm{O}$ spectra. Only the consistency between $\mathrm{Cr}$ and Fe oxides amounts and $\mathrm{O}$ intensity was verified.

Fig. 4 presents the intensity variation of all core level components measured as a function of oxygen exposure at the three temperatures and $45^{\circ}$ take-off angle. Fig. 4 (a) shows the variation of the total area of the $\mathrm{O} 1 \mathrm{~s}$ and $\mathrm{Ni} 2 \mathrm{p}_{3 / 2}$ core levels. The $\mathrm{O}$ 1s intensity increases until saturation at RT and near saturation at 150 and $250^{\circ} \mathrm{C}$. The saturation level increases with increasing temperature, in agreement with the variation observed during the real-time monitoring as presented in Fig. 2. Concerning nickel, the observed continuous intensity decrease with ongoing oxidation is consistent with continuous attenuation of the signal by the growing $\mathrm{Ni}$-free oxide film. No oxide of $\mathrm{Ni}$ was formed compared to $\mathrm{Fe}$ or $\mathrm{Cr}$ which is in agreement with their standard Gibbs energy of formation.

Fig. 4 (b) shows the variation of the Fe $2 \mathrm{p}_{3 / 2}$ metal and oxide core level components at the three temperatures. At RT, the $\mathrm{Fe}^{2+}$ and $\mathrm{Fe}^{3+}$ components first increase simultaneously $(0.5 \mathrm{~L})$. The increase of the $\mathrm{Fe}^{2+}$ component is stopped already at $3 \mathrm{~L}$ whereas that of the $\mathrm{Fe}^{3+}$ component goes on until saturation at $14 \mathrm{~L}$. A higher temperature promotes the increase of the $\mathrm{Fe}^{3+}$ component but barely that of the $\mathrm{Fe}^{2+}$ component. This shows that Fe$18 \mathrm{Cr}-13 \mathrm{Ni}(100)$ sample is first oxidized to simultaneously form $\mathrm{Fe}^{2+}$ and $\mathrm{Fe}^{3+}$ species in the nucleation phase. Then, with further $\mathrm{O}_{2}$ exposure, $\mathrm{Fe}^{3+}$ is preferentially formed possibly by oxidation of preformed $\mathrm{Fe}^{2+}$. This possibility implies that $\mathrm{Fe}^{2+}$ is still formed from metallic Fe since still observed with ongoing oxidation. Another possibility would be that $\mathrm{Fe}^{3+}$ could be produced directly from metallic Fe. In both cases, a higher temperature would promote the oxidation reaction to $\mathrm{Fe}^{3+}$ and atomic transport leading to the increase of the oxide quantity formed at saturation. The continuous intensity decrease with ongoing oxidation of the metallic $\mathrm{Fe}^{0}$ component is consistent with continuous attenuation of photoelectrons signal by the growing oxide species.

The variation of $\mathrm{Cr}^{3+}$ ( $\mathrm{Cr}$ oxides), $\mathrm{CrN}$ and $\mathrm{Cr}$ metal component intensities is presented in Fig. 4 (c). The $\mathrm{Cr}^{3+}$ oxide intensity increases rapidly in the nucleation phase for exposure 
(a) Variation of $\mathrm{O} 1 \mathrm{~s}$ and $\mathrm{Ni} 2 \mathrm{p}_{3 / 2}$
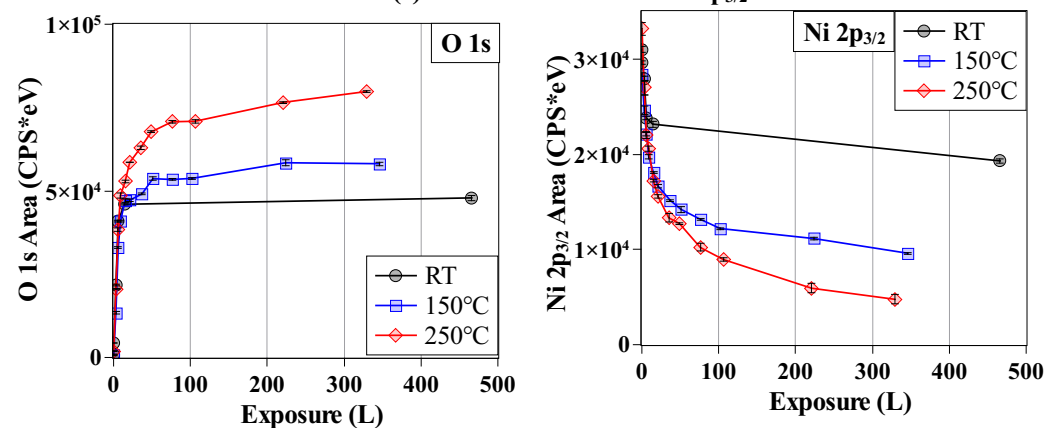

(b) Variation of Fe components
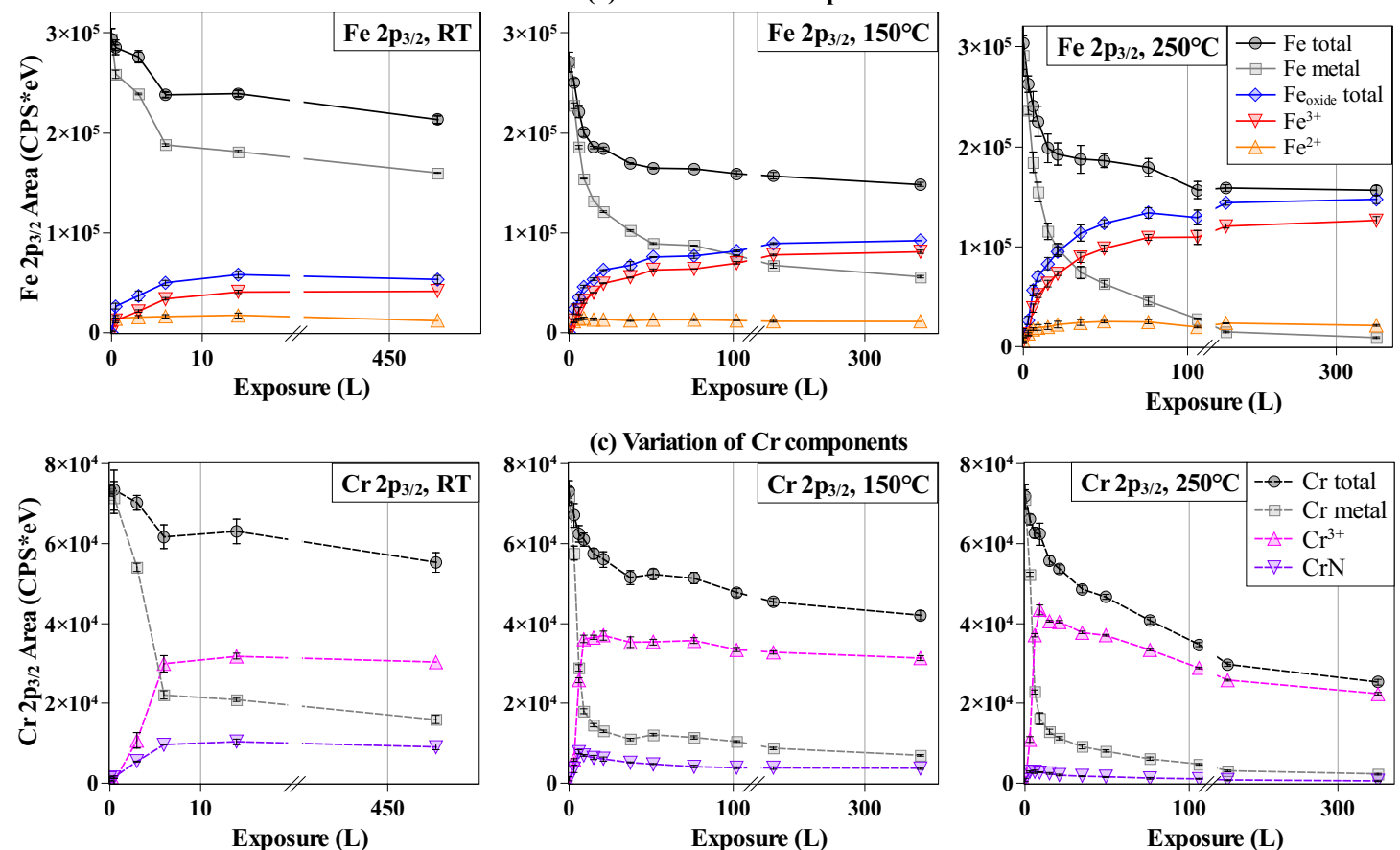

(c) Variation of $\mathrm{Cr}$ components
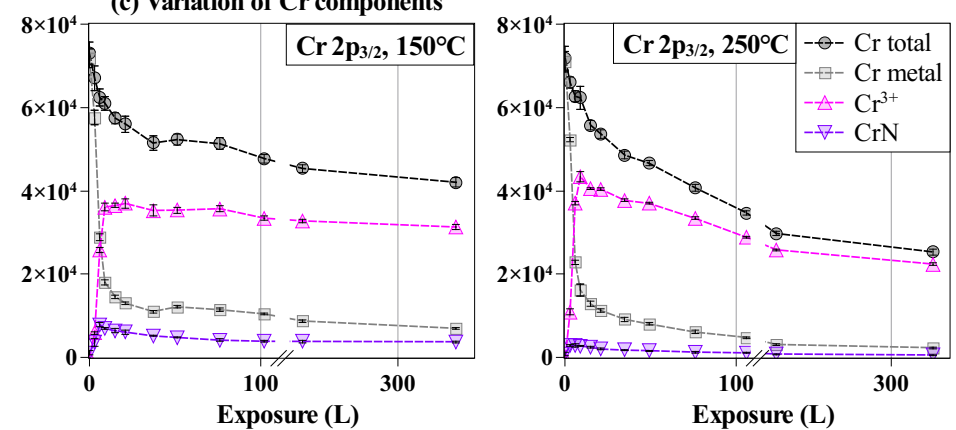

(d) Variation of $\mathrm{N}$ components
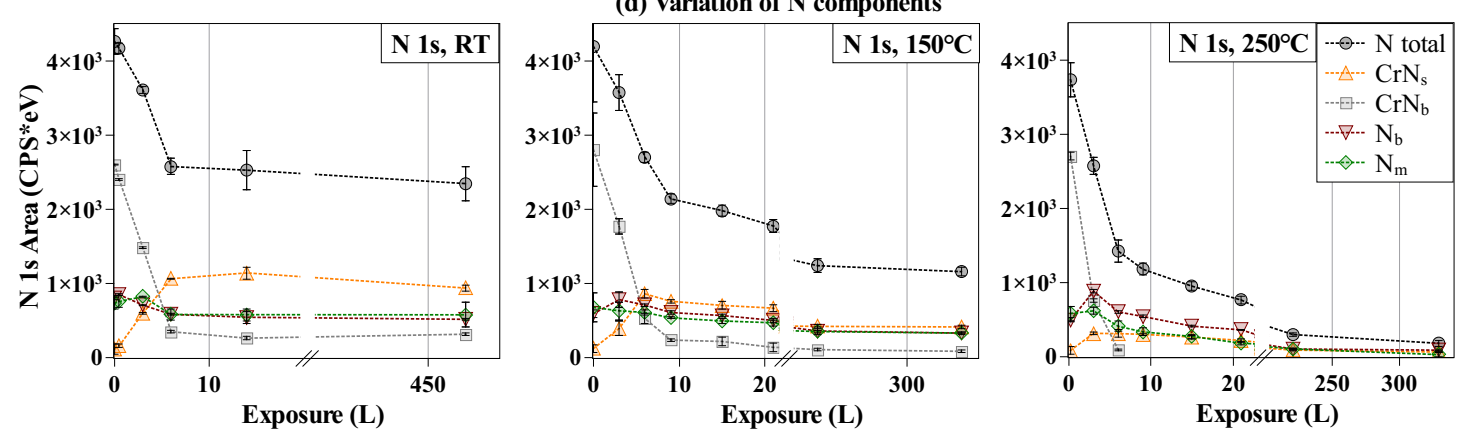

Fig. 4. Intensity variation of XPS core level components with increasing oxygen exposure at RT, $150^{\circ} \mathrm{C}$, $250^{\circ} \mathrm{C}$ : (a) $\mathrm{O} 1 \mathrm{~s}$ and $\mathrm{Ni} 2 \mathrm{p}_{3 / 2}$; (b) $\mathrm{Fe} 2 \mathrm{p}_{3 / 2}$; (c) $\mathrm{Cr} 2 \mathrm{p}_{3 / 2}$; (d) N 1s. Take-off angle: $45^{\circ}$. 
below $10 \mathrm{~L}$ and then levels off at higher exposure. A diminution is even observed with ongoing exposure at 150 and $250^{\circ} \mathrm{C}$. There are two reasons for this diminution: $\mathrm{Cr}^{3+}$ formation slows down while $\mathrm{Fe}^{3+}$ still forms and/or the $\mathrm{Fe}^{3+}$ oxides form above the $\mathrm{Cr}^{3+}$ oxides attenuating the $\mathrm{Cr}^{3+}$ signal. The same evolution is found for the nitride component as for the oxide $\mathrm{Cr}^{3+}$ component at all three temperatures. Comparing the consumption of metallic $\mathrm{Cr}^{0}$ and $\mathrm{Fe}^{0}$, it can be deduced that, in the studied temperature range, chromium is preferentially oxidized at the very beginning of oxidation in the nucleation phase below $10 \mathrm{~L}$. For exposure above $10 \mathrm{~L}$, a higher temperature promotes the preferential formation of $\mathrm{Fe}^{3+}$-containing oxides.

Fig. 4 (d) shows the evolution of the nitrogen component intensities with oxygen exposure. $\mathrm{CrN}_{b}$, as the main product of $\mathrm{Cr}-\mathrm{N}$ co-segregation at the prepared initial surface, sharply decreases in intensity for the exposure below $10 \mathrm{~L}$, and even almost disappears after $6 \mathrm{~L}$ at $250^{\circ} \mathrm{C}$. In contrast, $\mathrm{CrN}_{s}$ increases in intensity and becomes the predominant nitride species, before being attenuated by the oxide film still growing above $10 \mathrm{~L}$ exposure at 150 and $250{ }^{\circ} \mathrm{C} . \mathrm{N}_{m}$ presents a similar intensity variation to $\mathrm{N}_{b}$, supporting the assumption that it is related to minority structures associated to $\mathrm{N}$ in solution. It is concluded from the drop in intensity of all $\mathrm{N}$ components with increasing exposure to oxygen above $10 \mathrm{~L}$ exposure at 150 and $250{ }^{\circ} \mathrm{C}$ that the surface oxides develop above the remaining surface nitrides.

To sum up, these data show that the initial build-up of the surface oxide proceeds in the range of exposure below $10 \mathrm{~L}$ by simultaneous oxidation of iron and chromium. In this nucleation stage, $\mathrm{Cr}^{3+}$ formation is preferential over $\mathrm{Fe}^{3+}$ and $\mathrm{Fe}^{2+}$ formation. $\mathrm{Fe}^{2+}$ formation is mostly observed in the very first stage of oxidation $(0.5 \mathrm{~L})$. Afterwards, only $\mathrm{Fe}^{3+}$ is produced by further oxidation. Beyond $10 \mathrm{~L}$ of exposure to oxygen in the oxide growth regime, the competitive oxidation switches in favor of $\mathrm{Fe}^{3+}$ formation. Increasing the temperature (at $150^{\circ} \mathrm{C}$ and $250^{\circ} \mathrm{C}$ ) increases the oxidation rate and quantity of formed oxide without modifying the competitive oxidation sequence. Surface oxidation destabilizes the 3D surface nitrides produced by surface preparation and the oxide films grow above the remaining 2D interfacial nitrides. No oxidized nickel enters the composition of the oxide films. 

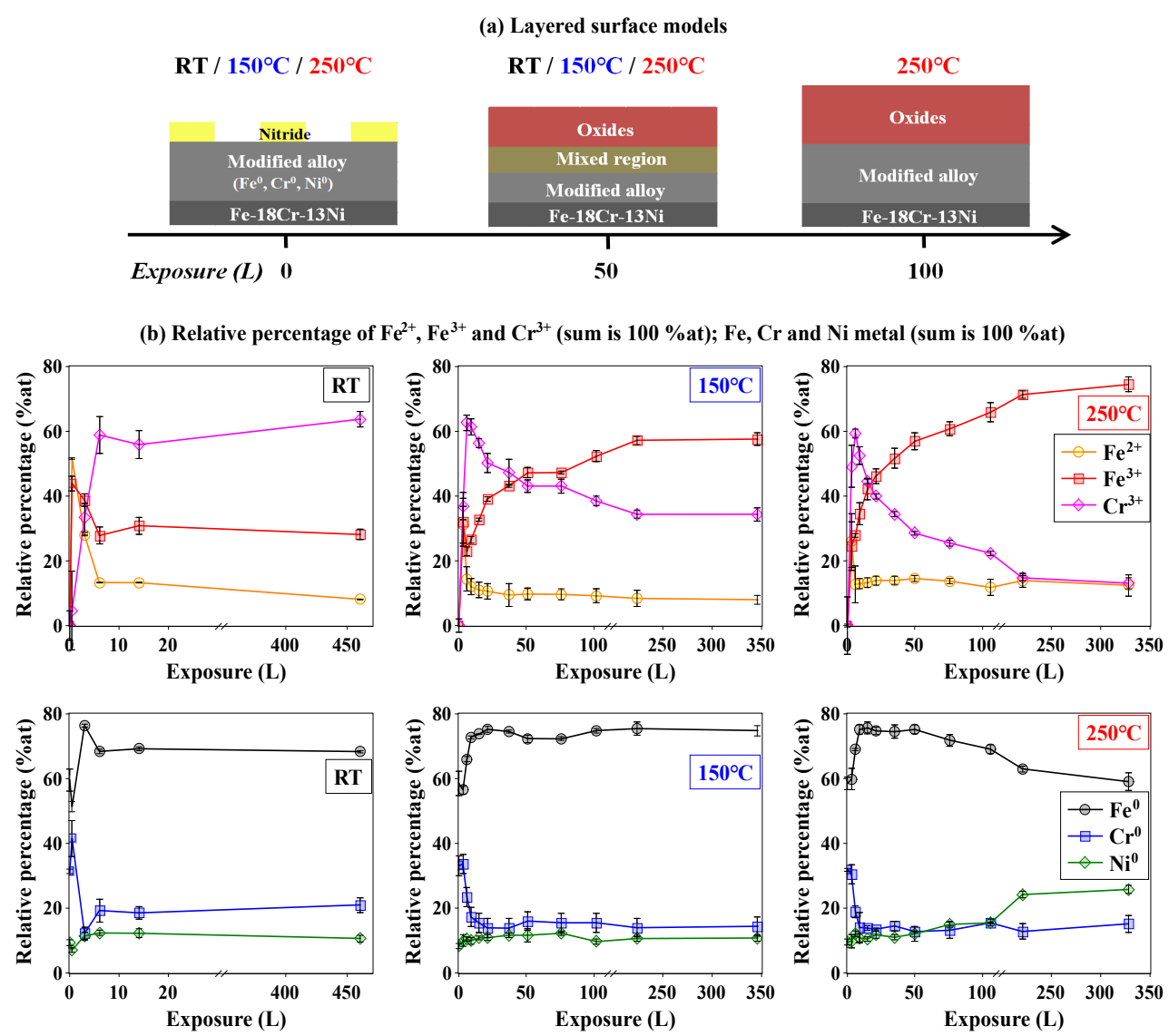

Fig. 5. (a) Layered models of the Fe-18Cr-13Ni(100) surface after 0-100 L exposure to oxygen: bulk (Fe$18 \mathrm{Cr}-13 \mathrm{Ni}$ ), modified alloy region (different concentration of alloy elements compared to bulk), mixed region (consisting of nitride, oxide and metallic components) and oxides region. (b) Variation of the relative concentrations of $\mathrm{Fe}, \mathrm{Cr}$ and $\mathrm{Ni}$ compounds in metal and oxide phases with increasing exposure to oxygen at $\mathrm{RT}, 150^{\circ} \mathrm{C}$ and $250^{\circ} \mathrm{C}$. The total percentage of metallic or oxide compounds is equal to 100 at\%.

\subsubsection{Layered surface composition}

Although previous studies $[16,19,20,22,24]$ have shown that no abrupt interface is formed between oxide and metal, layered models have been widely applied to describe the stratification of oxidized surfaces and quantify their composition. In this work, we have performed comparative analysis of the XPS intensities measured at $45^{\circ}$ and $90^{\circ}$ take-off angles of the emitted photoelectrons for each chemical component in order to define its relative distribution along the surface normal and thus to determine the in-depth distribution of the surface species. 
Layered models were applied to quantify the surface composition and equivalent oxide film thickness. The resulting values do not account for the inhomogeneity of the growth process that can be expected due to local structural and chemical variations at the alloy surface, in particular in the nucleation phase. This aspect will be discussed separately in an article based on STM data. Still, the values reported hereafter allow us to discuss the highly relevant aspect of chromium enrichment and its variation with the build-up of the oxide film.

Fig. 5 (a) presents the layered models of surface composition that were used for the clean annealed surface and the surface oxidized up to $100 \mathrm{~L}$ exposure at RT, $150^{\circ} \mathrm{C}$ and $250^{\circ} \mathrm{C}$. For all three temperatures, the layered surface composition was modeled with 3 regions: the oxide region, the mixed region (consisting of nitride, oxide and metallic components) and the modified alloy region where the compositions of alloy elements differ from that in the bulk alloy. This classical model of the top oxide layer covering the modified alloy layer with a mixed inter region as a transition between oxide and metal has been used in previous studies [17-20, 22, 24]. Prior to oxidation (0 L), the two-dimensional chromium nitride is formed at the outermost surface and the alloy is modified due to the co-segregation of $\mathrm{Cr}$ and N. Upon oxidation, an intermediate region mixing metal, oxide and nitride species is observed up to $50 \mathrm{~L}$ exposure at the interface between oxide and modified alloy; the nitride signal becomes totally attenuated by the top oxide layer for an exposure of about $100 \mathrm{~L}$ at $250^{\circ} \mathrm{C}$. Upon higher exposure at $150^{\circ} \mathrm{C}$ and $250^{\circ} \mathrm{C}$, the models are unchanged.

Assuming a homogeneous composition for both oxide and modified alloy layers, composition and equivalent oxide film thickness may be calculated. Variations of the relative concentration of $\mathrm{Fe}, \mathrm{Cr}$ and $\mathrm{Ni}$ compounds in metallic and oxide phases as a function of exposure are shown in Fig. 5 (b). The equivalent thickness values were calculated from the intensity ratios between the metal and oxide components of the $\mathrm{Fe}$ and $\mathrm{Cr} 2 \mathrm{p}_{3 / 2}$ core level based on the exponential attenuation of the photoelectron intensity with depth $[15,55,56]$. These thicknesses are given in Fig. 6.

These composition and thickness results should be taken with caution as they are calculated from a simplified model. However these quantities are relevant for comparison with 
previous studies and relative changes in concentrations help us to understand the underlying mechanism that govern the oxide growth process.

Based on an analysis of angular dependent photoemission spectra, a more precise model of the surface may be proposed. Fig. 6 presents the schematic view of the species distribution as a function of oxygen exposure at RT, $150^{\circ} \mathrm{C}$ and $250^{\circ} \mathrm{C}$. This is the first complete stratification scheme of oxidized surface of a stainless steel at the initial oxidation stage.

The equivalent thicknesses of the oxide regions ranges between 1.1-2.2 nm, calculated based on a simplified homogeneous model including the interfacial oxide/metal mixed region. This is consistent with oxide films reported to be 1-4 nm thick when formed on Fe or Fe-base alloys $[16,17,19,20,22-24,36,57]$. At RT, the calculated thickness is stable at $1.6-1.7$ $\mathrm{nm}$ after the $6 \mathrm{~L}$ exposure, in agreement with the saturation observed in the oxygen uptake (Fig. 2 and 4) and with 1.8-2 nm thickness reported for the native oxide film formed on the same austenitic stainless steel surface [23]. At 150 and $250^{\circ} \mathrm{C}$, the oxide equivalent thickness increases with exposure also following the same trend as the oxygen uptake (Fig. 2). However, the increase observed in the oxygen uptake at saturation with temperature increasing to 150 and $250^{\circ} \mathrm{C}$ (Fig. 4) is not reproduced by the calculated thickness which yields similar values of $2.0-2.1 \mathrm{~nm}$. A possible explanation is that the simplified model used for calculation does not accurately account for the deviation of the morphology of the surface oxides grown at 150 and $250^{\circ} \mathrm{C}$ from a continuous and uniformly thick film. This suggests that the films grown at higher temperature may include 3D oxide islands and thus may be non-uniform in thickness.

On the as-prepared surface (0 L), the modified region is enriched in metallic $\mathrm{Cr}$ (29 at\% instead of 18 at\% in the bulk alloy) and stratified. Metallic $\mathrm{Cr}$ is found concentrated in the upper part of the modified alloy region due to co-segregation with nitrogen after annealing at $700^{\circ} \mathrm{C}$. The two-dimensional $\mathrm{CrN}_{s}$ component is located on the topmost surface; while the three-dimensional $\mathrm{CrN}_{b}$ component and interstitial nitrogen $\mathrm{N}_{b}$ are found in this Cr-enriched upper part. Metallic Fe is found to be concentrated just below the Cr-enriched upper part while metallic Ni concentrates at the bottom of the modified alloy region. After oxidation at 150 and $250^{\circ} \mathrm{C}$, our angular analysis shows that these nitrogen species are included in the 


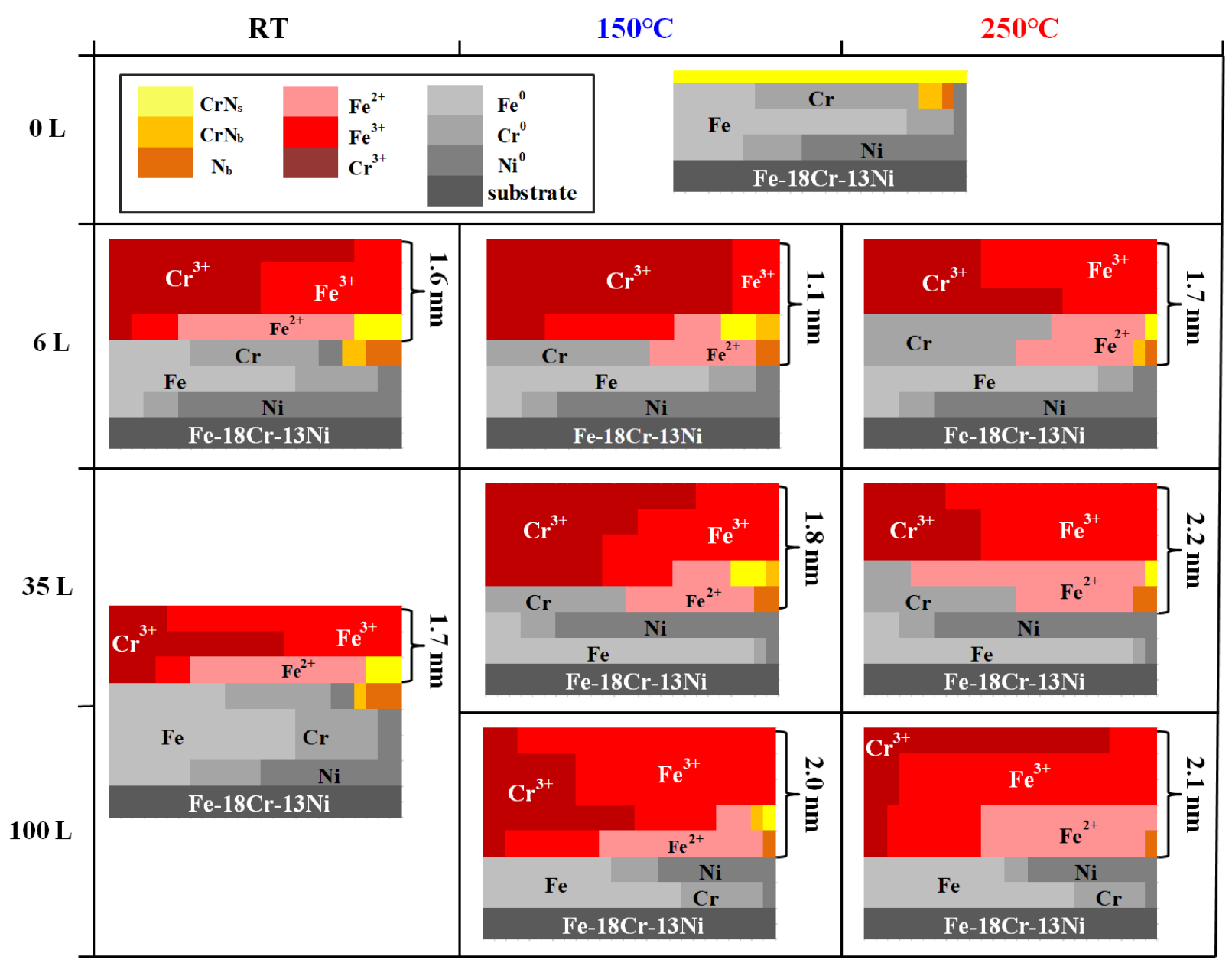

Fig. 6. Schematic stratification profiles of the Fe-18Cr-13Ni(100) surface after 0-100 L exposure to oxygen at $\mathrm{RT}, 150^{\circ} \mathrm{C}$ and $250^{\circ} \mathrm{C}$. The color blocks areas represent the relative proportions of components in the oxide and modified alloy regions. The equivalent thickness of oxide region (calculated from layered models in Fig. 5) is indicated on the right. 
mixed interfacial region developed between growing oxide and modified alloy. Only at RT, $\mathrm{CrN}_{b}$ and $\mathrm{N}_{b}$ remain in the upper part of the modified alloy region underneath the oxide.

According to previous studies [22, 24], there would be no clear separation between $\mathrm{Cr}$ oxide and $\mathrm{Fe}$ oxide in the oxidized surface. An amorphous oxide $\mathrm{FeCr}_{2} \mathrm{O}_{4}$-like phase could exist after a large exposure at a higher temperature $\left(1000 \mathrm{~L}, 300^{\circ} \mathrm{C}\right)[20]$. However, our angleresolved analysis supports the formation of layered surface oxides with different relative positions of the $\mathrm{Cr}^{3+}, \mathrm{Fe}^{3+}$ and $\mathrm{Fe}^{2+}$ species. The mechanisms by which the component distribution varies under very low exposure at the three studied temperatures are as follows.

Upon oxidation at RT, the surface oxide is found markedly enriched in $\mathrm{Cr}^{3+}$ already after an oxygen exposure of $6 \mathrm{~L}$ as a result of the preferential oxidation of chromium due to their relative standard Gibbs energy of formation. The cation fraction of $\mathrm{Cr}^{3+}$ in the oxide is then calculated as 59 at\%. $\mathrm{Fe}^{2+}$ and $\mathrm{Fe}^{3+}$ oxide species are also formed by competitive oxidation but in lower amounts. Their fractions are 13 at\% and 28 at\%, respectively. The $\mathrm{Fe}^{2+}$ oxide species are found mixed with the $\mathrm{CrN}_{s}$ species in the interfacial layer underneath the $\mathrm{Cr}^{3+}$ and $\mathrm{Fe}^{3+}$ mixed layer, likely as a result of their competitive formation on the bare metallic surface in the very first oxidation step $(0.5 \mathrm{~L})$ as discussed above. Further oxidation beyond saturation has little effect on the layered oxidized structure and composition. The cation fraction is 56 at\% for $\mathrm{Cr}^{3+}, 13$ at\% for $\mathrm{Fe}^{2+}$ and 31 at\% for $\mathrm{Fe}^{3+}$ at $35 \mathrm{~L}$. The modified alloy region has an unchanged concentration of $68 \% \mathrm{Fe}-19 \% \mathrm{Cr}-13 \% \mathrm{Ni}$ at $6 \mathrm{~L}$ and $69 \% \mathrm{Fe}-19 \% \mathrm{Cr}-$ $12 \% \mathrm{Ni}$ at $35 \mathrm{~L}$ if we assume a homogeneous distribution of species, still not depleted in $\mathrm{Cr}$ and with a Cr-enriched metallic layer at the top. This means that the surface saturated with oxygen at RT has still the capacity to form Cr oxides in order to grow a protective surface layer.

Upon oxidation at $250^{\circ} \mathrm{C}$, the same layered structure of oxide film is found with a mixed $\mathrm{Cr}^{3+} / \mathrm{Fe}^{3+}$ layer above the $\mathrm{Fe}^{2+}$-containing interfacial layer. Moreover, the results show that the structure is determined not only by the competitive oxidation of $\mathrm{Cr}$ and $\mathrm{Fe}$, but also by their atomic mobility. At $6 \mathrm{~L}$ (Fig. 6), metallic $\mathrm{Cr}$ is found preferentially in the interfacial region containing $\mathrm{Fe}^{2+}$ and Cr-nitrides, suggesting its transport from the modified alloy region in order to sustain $\mathrm{Cr}$ oxidation since the oxide film is equally enriched in chromium 
(the cation fraction is 59 at\% for $\mathrm{Cr}^{3+}, 13$ at\% for $\mathrm{Fe}^{2+}$ and 28 at\% for $\mathrm{Fe}^{3+}$ in Fig. 5 (b)). As a result, the modified alloy region is enriched with metallic Fe in its upper part. Thus, the competitive oxidation of iron is promoted gradually after $10 \mathrm{~L}$ exposure and Fe oxidation prevails over $\mathrm{Cr}$ oxidation at the oxide-metal interface. As a result, the $\mathrm{Cr}$ enrichment in the growing oxide film decreases with cation fractions of $34 \mathrm{at} \%$ for $\mathrm{Cr}^{3+}, 14$ at\% for $\mathrm{Fe}^{2+}$ and $52 \mathrm{at} \%$ for $\mathrm{Fe}^{3+}$ after $35 \mathrm{~L}$ exposure, and the interfacial region and the upper part of the modified alloy regions become depleted in metallic Cr. Subsequent oxygen exposure (> $50 \mathrm{~L})$ still preferentially consumes Fe leading to further decrease of the Cr enrichment in the growing oxide film with cation fractions of $22 \mathrm{at} \%$ for $\mathrm{Cr}^{3+}, 12 \mathrm{at} \%$ for $\mathrm{Fe}^{2+}$ and 66 at\% for $\mathrm{Fe}^{3+}$ after $106 \mathrm{~L}$. At this exposure, the $\mathrm{Fe}^{3+}$-rich oxide is found predominantly below the $\mathrm{Cr}^{3+}$-rich oxide, which suggests its preferential formation at the oxide-metal interface, i.e. under the $\mathrm{Cr}$ oxide. The metallic fraction in the modified alloy region below the oxide varies from $69 \% \mathrm{Fe}-19 \% \mathrm{Cr}-12 \% \mathrm{Ni}$ at $6 \mathrm{~L}$ to $74 \% \mathrm{Fe}-14 \% \mathrm{Cr}-12 \% \mathrm{Ni}$ at $35 \mathrm{~L}$ and $68 \% \mathrm{Fe}-$ $16 \% \mathrm{Cr}-16 \% \mathrm{Ni}$ at $106 \mathrm{~L}$, indicating that iron is relatively stable, chromium consumed and $\mathrm{Ni}$ enriched. These variations suggest that Fe oxidation is sustained by diffusion of metallic Fe from sub-surface region to the modified alloy region, whereas that of $\mathrm{Cr}$ is much less so possibly due to slower diffusion. The slight enrichment of $\mathrm{Ni}$ is detected in the Cr-depleted region, similarly to the $\mathrm{Ni}$ segregation reported in a study of Fe-20Cr-18Ni oxidation at $300^{\circ} \mathrm{C}[20]$. We conclude from these data obtained at $250^{\circ} \mathrm{C}$ that the oxide film growth and resulting surface composition are ruled by thermodynamically-dominated competitive oxidation of $\mathrm{Cr}$ and Fe in the very first stages like at RT. When oxygen exposure exceeds $50 \mathrm{~L}$, Fe oxide formation at oxide-metal interface becomes dominant and dependent on diffusion in the modified alloy region. This dependence of the competition between Cr oxidation and Fe oxidation over exposure is consistent with transformation from thermodynamically dominated to kinetically controlled reaction processes [35].

According to our kinetics results discussed above, the oxide film growth at $150^{\circ} \mathrm{C}$ is intermediate between those at RT and $250^{\circ} \mathrm{C}$. Similarly to the results obtained at RT and $250^{\circ} \mathrm{C}$, the oxide is enriched in $\mathrm{Cr}^{3+}$ in the earliest stage of oxidation with cation fractions of $63 \mathrm{at} \%$ for $\mathrm{Cr}^{3+}, 14$ at\% for $\mathrm{Fe}^{2+}$ and 23 at\% for $\mathrm{Fe}^{3+}$ at $6 \mathrm{~L}$. The modified alloy region 
is still not depleted in chromium with a concentration of $66 \% \mathrm{Fe}-23 \% \mathrm{Cr}-11 \% \mathrm{Ni}$. For the exposure of about $40 \mathrm{~L}$, the oxide enrichment in $\mathrm{Cr}^{3+}$ decreases (cation fractions of 48 at\% for $\mathrm{Cr}^{3+}, 9$ at\% for $\mathrm{Fe}^{2+}$ and 43 at\% for $\mathrm{Fe}^{3+}$ ) like at $250^{\circ} \mathrm{C}$ with $\mathrm{Cr}$ depletion in the modified metallic alloy $(73 \% \mathrm{Fe}-15 \% \mathrm{Cr}-12 \% \mathrm{Ni})$. For further exposure $(>50 \mathrm{~L})$, the $\mathrm{Cr}^{3+}$ enrichment still decreases in the oxide (cation fractions of 39 at\% for $\mathrm{Cr}^{3+}, 9$ at\% for $\mathrm{Fe}^{2+}$ and 52 at\% for $\mathrm{Fe}^{3+}$ ) owing to preferential $\mathrm{Fe}$ oxidation. The $\mathrm{Cr}$ concentration in the modified metallic layer is unchanged $(75 \% \mathrm{Fe}-14 \% \mathrm{Cr}-11 \% \mathrm{Ni})$. This confirms that the preferential consumption of iron by oxidation is compensated by diffusion from the sub-surface to the modified alloy region. Like at $250^{\circ} \mathrm{C}$, Ni becomes concentrated in the upper part of the modified alloy region. A noticeable difference with the oxide film grown at $250^{\circ} \mathrm{C}$ is the preferential formation of $\mathrm{Fe}^{3+}$ oxide at the topmost surface, as at RT. This suggests that at $150^{\circ} \mathrm{C}$ iron transport through the $\mathrm{Cr}^{3+} / \mathrm{Fe}^{3+}$ oxides is dominant for the oxide growth for exposures larger than $35 \mathrm{~L}$, whereas at $250^{\circ} \mathrm{C}$ oxygen transport to the oxide-metal interface would be dominant.

Table 2 compiles the data of surface composition and thickness obtained in this work, the data for a native oxide film formed by exposure to ambient air and a passive film formed by anodic polarization on the same alloy surface at RT, and the data for a thermal oxide film formed by exposing a Fe-17Cr alloy surface to oxygen at $327^{\circ} \mathrm{C}$. At RT, the surface saturated under oxygen in the present work is found more enriched in $\mathrm{Cr}^{3+}$ than the surface aged for $20 \mathrm{~h}$ under ambient air [23]. This can be assigned, at least partly, to the Cr-N co-segregation resulting from surface preparation in our work and that would promote the selective oxidation of chromium as previously reported [22]. However, the oxide film grown at RT under oxygen in the present work in much less enriched in $\mathrm{Cr}^{3+}$ than a passive film produced in acidic aqueous solution [23], which can be assigned to the absence of preferential dissolution of iron oxides promoting chromium enrichment in acidic media, as also found on a ferritic Fe-17Cr alloy oxide film grown by exposure to oxygen [22] and anodic polarization [58]. With the increase of temperature to $250^{\circ} \mathrm{C}$, it is found in the present work that the chromium oxidation is hindered by the depletion of metallic $\mathrm{Cr}$ underneath the growing oxide layer, while the diffusion of metallic Fe from the bulk enables to sustain iron oxidation, thus 
Table 2 Thickness and chemical composition (at\%) of thermal oxide film, native oxide film and passive oxide film formed on Fe-18Cr-13Ni(100) and Fe-17Cr, assuming homogeneous distribution of species

\begin{tabular}{|c|c|c|c|c|c|}
\hline Sample & Temperature & $\begin{array}{l}\text { Experimental } \\
\text { condition }\end{array}$ & $\begin{array}{c}\text { Thickness } \\
(\mathrm{nm})\end{array}$ & $\begin{array}{c}\text { Oxide } \\
\text { composition }\end{array}$ & $\begin{array}{l}\text { Modified } \\
\text { metallic phase }\end{array}$ \\
\hline \multirow{3}{*}{ Fe-18Cr-13Ni(100) } & \multirow{3}{*}{$\mathrm{RT}$} & $\mathrm{O}_{2}, 100 \mathrm{~L}^{*}$ & 1.7 & $56 \% \mathrm{Cr}_{\mathrm{ox}}-44 \% \mathrm{Fe}_{\mathrm{ox}}$ & $69 \mathrm{Fe}-19 \mathrm{Cr}-12 \mathrm{~N}$ \\
\hline & & Air, $20 \mathrm{~h}[23]$ & 2.0 & $21 \% \mathrm{Cr}_{\mathrm{ox}}-79 \% \mathrm{Fe}_{\mathrm{ox}}$ & $50 \mathrm{Fe}-19 \mathrm{Cr}-31 \mathrm{~N}$ \\
\hline & & $\begin{array}{l}0.5 \mathrm{M} \mathrm{H}_{2} \mathrm{SO}_{4}, 20 \mathrm{~h} \\
+500 \mathrm{mV} / \mathrm{SHE}[23]\end{array}$ & 2.3 & $91 \% \mathrm{Cr}_{\mathrm{ox}}-7 \% \mathrm{Fe}_{\mathrm{ox}}$ & $50 \mathrm{Fe}-15 \mathrm{Cr}-35 \mathrm{Ni}$ \\
\hline \multirow{3}{*}{ Fe-18Cr-13Ni(100) } & \multirow{3}{*}{$250^{\circ} \mathrm{C}$} & $\mathrm{O}_{2}, 6 \mathrm{~L}^{*}$ & 1.7 & $59 \% \mathrm{Cr}_{\text {ox }}-41 \% \mathrm{Fe}_{\text {ox }}$ & $69 \mathrm{Fe}-19 \mathrm{Cr}-12 \mathrm{~N}$ \\
\hline & & $\mathrm{O}_{2}, 35 \mathrm{~L}^{*}$ & 2.2 & $34 \% \mathrm{Cr}_{\mathrm{ox}}-66 \% \mathrm{Fe}_{\mathrm{ox}}$ & $74 \mathrm{Fe}-14 \mathrm{Cr}-12 \mathrm{Ni}$ \\
\hline & & $\mathrm{O}_{2}, 100 \mathrm{~L}^{*}$ & 2.1 & $22 \% \mathrm{Cr}_{\text {ox }}-78 \% \mathrm{Fe}_{\text {ox }}$ & $68 \mathrm{Fe}-16 \mathrm{Cr}-16 \mathrm{~N}$ \\
\hline \multirow{4}{*}{$\mathrm{Fe}-17 \mathrm{Cr}$} & \multirow{3}{*}{$327^{\circ} \mathrm{C}$} & $\mathrm{O}_{2}, 10 \mathrm{~L}[22]$ & 1.0 & $45 \% \mathrm{Cr}_{\text {ox }}-55 \% \mathrm{Fe}_{\text {ox }}$ & $86 \mathrm{Fe}-14 \mathrm{Cr}$ \\
\hline & & $\mathrm{O}_{2}, 30 \mathrm{~L}[22]$ & 2.2 & $29 \% \mathrm{Cr}_{\text {ox }}-71 \% \mathrm{Fe}_{\text {ox }}$ & $86 \mathrm{Fe}-14 \mathrm{Cr}$ \\
\hline & & $\mathrm{O}_{2}, 100 \mathrm{~L}[22]$ & 3.5 & $17 \% \mathrm{Cr}_{\text {ox }}-83 \% \mathrm{Fe}_{\text {ox }}$ & $86 \mathrm{Fe}-14 \mathrm{Cr}$ \\
\hline & $\mathrm{RT}$ & $\begin{array}{l}2 \times 10^{-2} \mathrm{M} \mathrm{Cl}^{-}, 27 \mathrm{~h} \\
+390 \mathrm{mV} / \mathrm{SHE}^{2}[58]\end{array}$ & 3.1 & $75 \% \mathrm{Cr}_{\mathrm{ox}}-25 \% \mathrm{Fe}_{\mathrm{ox}}$ & $81 \mathrm{Fe}-19 \mathrm{Cr}$ \\
\hline
\end{tabular}

* This work

leading to a gradual decrease of the $\mathrm{Cr}^{3+}$ enrichment with increasing exposure. Compared to the thermal oxidation of a ferritic Fe-17Cr sample (also with surface nitrides) at $327^{\circ} \mathrm{C}$ [22], the variation of the $\mathrm{Cr}^{3+}$ enrichment on our austenitic sample follows the same trend.

\section{Conclusion}

Real-time monitoring of the evolution of a model 304 stainless steel monocrystal surface, Fe- $18 \mathrm{Cr}-13 \mathrm{Ni}(100)$, in the early stages of oxidation at $\mathrm{RT}, 150^{\circ} \mathrm{C}$ and $250^{\circ} \mathrm{C}$ was achieved using in situ XPS in Snapshot mode analysis and complemented by high resolution core level analysis of the growth mechanisms and Cr enrichment. The work revealed, for the first time to our knowledge, the mechanisms of stratification during the early build-up of the surface oxide on a model austenitic stainless steel surface at different temperatures.

The results show that, on the oxide-free surface, nitrogen segregation is detected upon heating at $400^{\circ} \mathrm{C}$ and increases significantly above $500^{\circ} \mathrm{C}$ to reach a saturation at $680^{\circ} \mathrm{C}$. The 
activation energy of nitrogen segregation is $72 \pm 5 \mathrm{~kJ} / \mathrm{mol}$. Marked Cr enrichment of the as prepared metallic surface was observed as a result of $\mathrm{Cr}$ segregation and $\mathrm{Cr}-\mathrm{N}$ co-segregation with $\mathrm{N}$ forming mainly three-dimensional $\mathrm{CrN}_{b}$ particles with minority two-dimensional $\mathrm{CrN}_{s}$ and interstitial nitrogen $\mathrm{N}_{b}$. Surface oxidation destabilizes the 3D chromium nitrides and the oxide films grow above the 2D surface nitrides remaining at the surface.

The temperature dependence of the surface oxygen uptake as measured by real-time monitoring evidences two regimes for the growth of the surface oxide. Up to about 10 $\mathrm{L}$ of oxygen exposure, the uptake is faster with a maximum at $2-5 \mathrm{~L}$ and decreases with increasing temperature, suggesting a nucleation regime of the surface oxide limited by oxygen adsorption. Beyond $10 \mathrm{~L}$, the uptake is saturated at RT but increases with temperature, suggesting a growth regime of the surface oxide limited by atomic displacement and mobility. The oxygen pressure in the range below $10^{-6}$ mbar is found to have no effect on the oxidation rate.

In the nucleation regime leading to saturation, $\mathrm{Cr}^{3+}$ formation is preferential over $\mathrm{Fe}^{3+}$ formation and $\mathrm{Fe}^{2+}$ formation is mostly observed in the very first stage of oxidation (0.5 L). Nickel is not oxidized. A surface layer of strongly $\mathrm{Cr}^{3+}$-enriched oxide is thus formed over the mainly $\mathrm{Fe}^{2+}$ oxide (FeO-like) species mixed with the $\mathrm{CrN}_{s}$ species in the interfacial layer underneath the $\mathrm{Cr}^{3+} / \mathrm{Fe}^{3+}$ mixed layer. Further oxidation beyond saturation at RT causes no marked evolution of the oxide layered structure, composition and thickness. The modified alloy region is still not depleted in metallic $\mathrm{Cr}$ and thus able to further grow a $\mathrm{Cr}^{3+}$-enriched protective surface layer.

At 150 and $250^{\circ} \mathrm{C}$, the oxide formed in the nucleation regime is also enriched in $\mathrm{Cr}^{3+}$ but the modified alloy region gets depleted with metallic $\mathrm{Cr}$. As a result, the competitive oxidation of iron is gradually promoted in the oxide growth regime leading to the decrease of the $\mathrm{Cr}^{3+}$ enrichment in the oxide. Fe oxidation is sustained by diffusion of metallic Fe from sub-surface region to the modified alloy region. At $150^{\circ} \mathrm{C}, \mathrm{Fe}^{3+}$ oxide was found to form at the topmost surface, whereas at $250^{\circ} \mathrm{C}$ it was at the oxide-metal interface, suggesting a switch of the oxide growth from predominant iron transport through the $\mathrm{Cr}^{3+} / \mathrm{Fe}^{3+}$ oxide at $150^{\circ} \mathrm{C}$ to predominant oxygen transport at $250^{\circ} \mathrm{C}$ for exposures beyond $35 \mathrm{~L}$. 


\section{Acknowledgments}

This project has received funding from the European Research Council (ERC) under the European Union's Horizon 2020 research and innovation program (ERC Advanced Grant No. 741123). Région Île-de-France is acknowledged for partial funding of the XPS equipment.

China Scholarship Council (CSC) is acknowledged for the scholarship to the first author (No. 201606380129).

\section{References}

[1] D. Macdonald, Passivity - The key to our metals-based civilization, Pure Appl. Chem. 71 (1999) 951 978.

[2] H. H. Strehblow, V. Maurice, P. Marcus, Passivity of metals, Corros. Technol., CRC Press, 2011, pp. $235-326$.

[3] P. Marcus, V. Maurice, Oxide passive films and corrosion protection, Wiley-VCH Verlag GmbH \& Co. KGaA, 2011, pp. $119-144$.

[4] V. Maurice, W. P. Yang, P. Marcus, XPS and STM study of passive films formed on Fe-22Cr(110) single-crystal surfaces, J. Electrochem. Soc. 143 (1996) 1182 - 1200.

[5] P. Marcus, M. E. Bussell, XPS study of the passive films formed on nitrogen-implanted austenitic stainless steels, Appl. Surf. Sci. 59 (1) (1992) $7-21$.

[6] I. Olefjord, The passive state of stainless steels, Mater. Sci. Eng. 42 (C) (1980) 161 - 171.

[7] I. Olefjord, B. O. Elfstrom, Composition of the surface during passivation of stainless steel, Corrosion 38 (1) (1982) $46-52$.

[8] I. Olefjord, B. O. Elfstrom, Investigation by ESCA of the passive film formed on austenitic stainless steel in oxygenated water, EUROCOR'77, Eur. Congr. on Met. Corros., 92nd Event of the Eur. Fed. of Corros. (1977) $21-28$.

[9] I. Olefjord, L. Wegrelius, Surface analysis of passive state, Corros. Sci. 31 (C) (1990) $89-98$.

[10] P. Jemmely, S. Mischler, D. Landolt, Tribocorrosion behaviour of Fe-17Cr stainless steel in acid and alkaline solutions, Tribol. Int. 32 (6) (1999) $295-303$.

[11] C. R. Clayton, G. P. Halada, J. R. Kearns, Passivity of high-nitrogen stainless alloys: the role of metal oxyanions and salt films, Mater. Sci. Eng., A 198 (1) (1995) 135 - 144.

[12] A. R. Brooks, C. R. Clayton, K. Doss, Y. C. Lu, On the role of Cr in the passivity of stainless steel, J. Electrochem. Soc. 133 (1986) $2459-2464$.

[13] J. E. Castle, C. R. Clayton, The use of in the X-ray photo-electron spectroscopy analyses of passive layers on stainless steel, Corros. Sci. 17 (1) (1977) 7 - 26. 
[14] T. Massoud, V. Maurice, L. H. Klein, A. Seyeux, P. Marcus, Nanostructure and local properties of oxide layers grown on stainless steel in simulated pressurized water reactor environment, Corros. Sci. $84(2014) 198-203$.

[15] V. Maurice, H. Peng, L. H. Klein, A. Seyeux, S. Zanna, P. Marcus, Effects of molybdenum on the composition and nanoscale morphology of passivated austenitic stainless steel surfaces, Faraday Discuss. $180(2015) 151-170$.

[16] J. R. Lince, S. V. Didziulis, D. K. Shuh, T. D. Durbin, J. A. Yarmoff, Interaction of $\mathrm{O}_{2}$ with the $\mathrm{Fe}_{0.84} \mathrm{Cr}_{0.16}$ (001) surface studied by photoelectron spectroscopy, Surf. Sci. 277 (1) (1992) $43-63$.

[17] T. C. Lin, G. Seshadri, J. A. Kelber, A consistent method for quantitative XPS peak analysis of thin oxide films on clean polycrystalline iron surfaces, Appl. Surf. Sci. 119 (12) (1997) 83 - 92.

[18] S. J. Roosendaal, B. van Asselen, J. W. Elsenaar, A. M. Vredenberg, F. H. P. M. Habraken, The oxidation state of $\mathrm{Fe}(100)$ after initial oxidation in $\mathrm{O}_{2}$, Surf. Sci. (1999) $329-337$.

[19] A. P. Grosvenor, B. A. Kobe, N. S. McIntyre, Examination of the oxidation of iron by oxygen using X-ray photoelectron spectroscopy and QUASES, Surf. Sci. 565 (23) (2004) 151 - 162.

[20] M. Lampimäki, K. Lahtonen, P. Jussila, M. Hirsimäki, M. Valden, Morphology and composition of nanoscale surface oxides on Fe-20Cr-18Ni(111) austenitic stainless steel, J. Electron. Spectrosc. Relat. Phenom. 154 (3) (2007) $69-78$.

[21] R. Davies, D. Edwards, J. Gräfe, L. Gilbert, P. Davies, G. Hutchings, M. Bowker, The oxidation of Fe(111), Surf. Sci. 605 (1718) (2011) $1754-1762$.

[22] H. Ali-Löytty, P. Jussila, M. Hirsimäki, M. Valden, Influence of CrN surface compound on the initial stages of high temperature oxidation of ferritic stainless steel, Appl. Surf. Sci. 257 (17) (2011) 7783 7791.

[23] V. Maurice, W. P. Yang, P. Marcus, X-ray photoelectron spectroscopy and scanning tunneling microscopy study of passive films formed on (100) Fe-18Cr-13Ni single-crystal surfaces, J. Electrochem. Soc. 145 (3) (1998) $909-920$.

[24] P. Jussila, K. Lahtonen, M. Lampimäki, M. Hirsimäki, M. Valden, Influence of minor alloying elements on the initial stages of oxidation of austenitic stainless steel materials, Surf. Interface Anal. 40 (8) (2008) $1149-1156$.

[25] M. Aronniemi, J. Sainio, J. Lahtinen, Chemical state quantification of iron and chromium oxides using XPS: the effect of the background subtraction method, Surf. Sci. 578 (13) (2005) 108 - 123.

[26] T. Yamashita, P. Hayes, Analysis of XPS spectra of $\mathrm{Fe}^{2+}$ and $\mathrm{Fe}^{3+}$ ions in oxide materials, Appl. Surf. Sci. 254 (8) (2008) $2441-2449$.

[27] B. P. Payne, M. C. Biesinger, N. S. McIntyre, X-ray photoelectron spectroscopy studies of reactions on chromium metal and chromium oxide surfaces, J. Electron. Spectrosc. Relat. Phenom. 184 (12) (2011) 
$29-37$.

[28] M. C. Biesinger, B. P. Payne, A. P. Grosvenor, L. W. M. Lau, A. R. Gerson, R. S. C. Smart, Resolving surface chemical states in XPS analysis of first row transition metals, oxides and hydroxides: Cr, Mn, Fe, Co and Ni, Appl. Surf. Sci. 257 (7) (2011) 2717 - 2730.

[29] A. P. Grosvenor, M. C. Biesinger, R. S. C. Smart, N. S. McIntyre, New interpretations of XPS spectra of nickel metal and oxides, Surf. Sci. 600 (9) (2006) 1771 - 1779.

[30] A. M. Salvi, J. E. Castle, J. F. Watts, E. Desimoni, Peak fitting of the chromium 2p XPS spectrum, Appl. Surf. Sci. 90 (3) (1995) 333 - 341.

[31] J. E. Castle, H. Chapman-Kpodo, A. Proctor, A. M. Salvi, Curve-fitting in XPS using extrinsic and intrinsic background structure, J. Electron. Spectrosc. Relat. Phenom. 106 (1) (2000) 65 - 80.

[32] I. Grohmann, E. Kemnitz, A. Lippitz, W. E. S. Unger, Curve fitting of Cr 2p photoelectron spectra of $\mathrm{Cr}_{2} \mathrm{O}_{3}$ and $\mathrm{CrF}_{3}$, Surf. Interface Anal. 23 (13) (1995) 887 - 891.

[33] E. Ünveren, E. Kemnitz, S. Hutton, A. Lippitz, W. E. S. Unger, Analysis of highly resolved X-ray photoelectron $\mathrm{Cr} 2 \mathrm{p}$ spectra obtained with a $\mathrm{Cr}_{2} \mathrm{O}_{3}$ powder sample prepared with adhesive tape, Surf. Interface Anal. 36 (1) (2004) 92 - 95.

[34] D. D. Wagman, W. H. Evans, V. B. Parker, R. H. Schumm, R. L. Nutall, The NBS tables of chemical thermodynamic properties, J. Phys. Chem. Ref. Data 11.

[35] G. C. Allen, S. J. Harris, J. A. Jutson, J. M. Dyke, A study of a number of mixed transition metal oxide spinels using X-ray photoelectron spectroscopy, Appl. Surf. Sci. 37 (1) (1989) 111 - 134.

[36] P. C. J. Graat, M. A. J. Somers, Simultaneous determination of composition and thickness of thin iron-oxide films from XPS Fe 2p spectra, Appl. Surf. Sci. 100/101 (1996) 36 - 40.

[37] P. Graat, M. Somers, Quantitative analysis of overlapping XPS peaks by spectrum reconstruction: Determination of the thickness and composition of thin iron oxide films, Surf. Interface Anal. 26 (1998) $773-782$.

[38] D. J. Coates, A. Hendry, The effect of dispersed nitrides on the oxidation of ferritic alloys, Corros. Sci. 22 (10) (1982) $973-989$.

[39] S. J. Roosendaal, A. M. Vredenberg, F. H. P. M. Habraken, The influence of adsorbed N in the initial stages of oxidation of iron, Surf. Sci. 402404 (1998) 135 - 139.

[40] D. J. Coates, B. Mortimer, A. Hendry, The oxidation and corrosion resistance of nitrided iron alloys, Corros. Sci. 22 (10) (1982) $951-972$.

[41] H. J. Grabke, R. Dennert, B. Wagemann, The effect of S, N, and C on the oxidation of Ni-20Cr and Fe-20Cr, Oxid. Met. 47 (5-6) (1997) 495 - 506.

[42] L. Ma, F. Wiame, V. Maurice, P. Marcus, to be published.

[43] www.casaxps.com. 
[44] T. Yamashita, P. Hayes, Effect of curve fitting parameters on quantitative analysis of $\mathrm{Fe}_{0.94} \mathrm{O}$ and $\mathrm{Fe}_{2} \mathrm{O}_{3}$ using XPS, J. Electron. Spectrosc. Relat. Phenom. 152 (12) (2006) 6 - 11.

[45] P. M. A. Sherwood, Curve fitting in surface analysis and the effect of background inclusion in the fitting process, J. Vac. Sci. Technol. A 14 (3) (1996) 1424-1432.

[46] D. A. Shirley, High-resolution X-ray photoemission spectrum of the valence bands of gold, Phys. Rev. B 5 (12) (1972) $4709-4714$.

[47] S. Doniach, M. Šunjić, Many-electron singularity in X-ray photoemission and X-ray line spectra from metals, J. Phys. C: Solid State Phys. 3 (2) (1970) 285 - 291.

[48] W. A. Jordaan, J. J. Terblans, H. C. Swart, The effect of nitrogen on the co-segregation with molybdenum in a Fe-3.5Mo-N(100) single crystal, S. Afr. J. Sci. 104 (2008) 393 - 397.

[49] A. P. Grosvenor, B. A. Kobe, N. S. McIntyre, Studies of the oxidation of iron by water vapour using X-ray photoelectron spectroscopy and QUASES, Surf. Sci. 572 (23) (2004) 217 - 227.

[50] J.-C. Dupin, D. Gonbeau, P. Vinatier, A. Levasseur, Systematic XPS studies of metal oxides, hydroxides and peroxides, Phys. Chem. Chem. Phys. 2 (2000) 1319 - 1324.

[51] I. Olefjord, ESCA-studies of the composition profile of low temperature oxide formed on chromium steels - I. Oxidation in dry oxygen, Corros. Sci. 15 (612) (1975) 687 - 696.

[52] E. Clauberg, J. Janověc, C. Uebing, H. Viefhaus, H. J. Grabke, Surface segregation on Fe-25Cr-2Ni0.14Sb-N,S(100) single crystal surfaces, Appl. Surf. Sci. 161 (12) (2000) $35-46$.

[53] C. Uebing, V. Scheuch, M. Kiskinova, H. P. Bonzel, Segregation of ordered CrN and CrC surface phases on a Fe-15Cr(100) crystal, Surf. Sci. 321 (1-2) (1994) $89-99$.

[54] C. Müller, C. Uebing, M. Kottcke, C. Rath, L. Hammer, K. Heinz, The structure of the surface compound $\mathrm{CrN}$ formed by cosegregation on a Fe-15Cr-N(100) single crystal surface, Surf. Sci. 400 (13) (1998) $87-94$.

[55] J. M. Hill, D. G. Royce, C. S. Fadley, L. F. Wagner, F. J. Grunthaner, Properties of oxidized silicon as determined by angular-dependent X-ray photoelectron spectroscopy, Chem. Phys. Lett. 44 (2) (1976) $225-231$.

[56] C. J. Powell, A. Jablonski, Progress in quantitative surface analysis by X-ray photoelectron spectroscopy: current status and perspectives, J. Electron. Spectrosc. Relat. Phenom. 178-179 (Supplement C) (2010) $331-346$.

[57] G. Bhargava, I. Gouzman, C. M. Chun, T. A. Ramanarayanan, S. L. Bernasek, Characterization of the native surface thin film on pure polycrystalline iron: a high resolution XPS and TEM study, Appl. Surf. Sci. 253 (9) (2007) $4322-4329$.

[58] W. P. Yang, D. Costa, P. Marcus, Chemical composition, chemical states, and resistance to localized corrosion of passive films on an Fe-17\%Cr alloy, J. Electrochem. Soc. 141 (1) (1994) 111 - 116. 